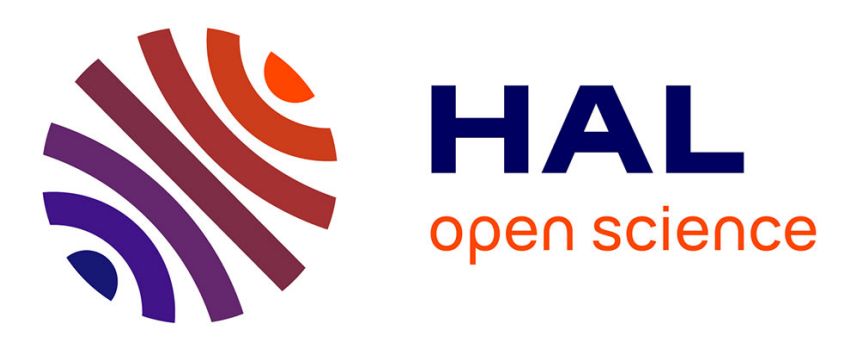

\title{
A Multi-Criteria Decision-Making Process for Project Risk Management Method Selection
}

\author{
Franck Marle, Thierry Gidel
}

\section{To cite this version:}

Franck Marle, Thierry Gidel. A Multi-Criteria Decision-Making Process for Project Risk Management Method Selection. International Journal of Multicriteria Decision Making, 2012, 2 (2), pp.189-223. 10.1504/IJMCDM.2012.046948 . hal-01171419

\section{HAL Id: hal-01171419 \\ https://hal.science/hal-01171419}

Submitted on 25 Aug 2015

HAL is a multi-disciplinary open access archive for the deposit and dissemination of scientific research documents, whether they are published or not. The documents may come from teaching and research institutions in France or abroad, or from public or private research centers.
L'archive ouverte pluridisciplinaire HAL, est destinée au dépôt et à la diffusion de documents scientifiques de niveau recherche, publiés ou non, émanant des établissements d'enseignement et de recherche français ou étrangers, des laboratoires publics ou privés. 


\title{
A Multi-Criteria Decision-Making Process for Project Risk Management Method Selection
}

\author{
Franck MARLE ${ }^{1}$, Thierry GIDEL ${ }^{2}$ \\ ${ }^{1}$ Ecole Centrale Paris, Laboratoire Genie Industriel, Grande voie des vignes, 92295 Chatenay-Malabry, France \\ ${ }^{2}$ Université Technologique de Compiègne, Costech - EA 2223, rue du Dr Schweitzer, Compiègne, 60200, France
}

\begin{abstract}
With projects facing tight constraints, uncertainty and change, they are more than ever exposed to risk. It has thus become increasingly important to effectively and efficiently manage project risks. Project risk management thus plays an important role in the quality and reliability of decisions made during a project. Our objective in this paper is to provide a project office manager or a project manager with one or more adequate Project Risk Management (PRM) methods. To do this, we propose a structured approach based on a multi-criteria decision analysis model to select these methods. Firstly, we propose a list of alternative PRM methods and a list of selection criteria. Secondly, we capture, by interviewing decision-makers, data about their organization and their preferences. Fuzzy numbers are used to express the relative importance of the criteria. Thirdly, the selection process is run by screening out inadequate methods and by ranking remaining alternatives. An application for one example is presented.
\end{abstract}

\section{Keywords}

Multi-criteria decision-making; fuzzy numbers; method selection; project risk management; risk identification; risk analysis; group decision-making; preference modeling 


\section{Introduction}

Standards like ISO 10006 (International Standards Organization), PMI (Project Management Institute) or IPMA (International Project Management Association) have established that project management consists in the planning, organization, monitoring, control and reporting of all the aspects of a project, and in the motivation of all people involved in reaching the project objectives (ISO 2003; IPMA 2006; PMI 2008). According to standards (PMI 2008; AFNOR 2003), project risk is defined as "an uncertain event or condition that, if it occurs, has a positive or negative effect on at least one of the project objectives". If these risks are not managed pro-actively using a structured approach, then they can result in serious consequences for the project, as outlined in ISO 10006 (ISO 2003 ).

Uncertainty, complexity and tight constraints are inherent to projects and make them risky. As the environment of a project evolves, there may be a gap between what is actually done and what was initially planned. This involves making some changes, whether in the targets or in the plans to reach them. This notion of change increases the risks that a project is facing. It is accepted today that Project Risk Management (PRM) has an important influence on project management as a decision-making process and on project success rate. PMI describes the PRM purpose as "the increase of probability and impact of positive events, and the decrease of probability and impact of negative events" (PMI 2008). It consists in the treatment of project uncertainties through a structured, fourstep generic approach:

- Risk identification describes identifiable risks, that is to say the potential events that could occur and lead to negative or positive impact on the project.

- Risk analysis analyzes causes and consequences of identified risks, in order to evaluate their criticality, mainly by assessing probability and impact.

- $\quad$ Risk treatment or response planning makes decisions about tasks, budgets and responsibilities in order to avoid, mitigate or transfer the most critical risks.

- $\quad$ Risk monitoring and control comprises follow-up, by the identified responsible persons, of risks and of the execution of planned actions, including their real impact on the criticality of the risks (effectiveness) and their potential secondary effects.

These processes are supported by concepts, tools and methods. Various methods have been developed: some standards have proposed risk management methods which are specific to project context or generic (IEC 1995; APM 1996; AFNOR 1999; PRINCE 1999; IEEE 2001; BSI 2002; IPMA 2006; PMI 2008). They have been introduced in different fields, like project management, systems analysis, design, insurance, food industry, information systems, chemical systems, and industrial safety. Yet, when looking at company practice, it can be observed that PRM methods are not widely used (Coppendale 1995; Lyons and Skitmore 2004). When a method is implemented on a project, it is often either imposed by a corporate standard or chosen by the project leader, since it has already been tested before. The issue is that the PRM method used in a company may have been chosen for the wrong reasons or for historical reasons which are obsolete in the current context. In this paper, we focus on the selection of a relevant PRM method. Our goal is to provide project office managers, project managers or project risk managers with a decision-making framework and its associated process to make the adequate choice.

The paper is organized as follows. The decision-making problem is introduced in Section 2, including our structured approach and the justification of our methodological choices. Section 3 enables the decision-making model to be built, including the identification of the criteria and the alternatives. Section 4 describes how data about the organization are captured and used to screen out PRM methods which are too difficult to implement. Section 5 screens out methods which do not fit with decision-makers' preferences.Section 6 ranks the remaining alternatives according to decision-makers' preferences. Section 7 presents an example of the application of the model to illustrate its benefits and limits. Finally, some conclusions and perspectives are drawn in section 8 . 


\section{Formulation of the multi-criteria decision-making problem}

The expertise required to choose a PRM method may be very deep, because of the use of some advanced concepts, like Markov chain, Monte-Carlo simulation or logical gates. Usually, only experts of the field are able to take full advantage of a PRM method. The issue of PRM methods choice becomes even more important when it is applied on a decentralized way, sometimes with local or web-based software, without any technical support, from a project office for instance, or a risk manager or an expert. Both the characteristics of PRM methods and preferences of the decision-maker are to be modeled.

The goal is to use a Multi Criteria Decision Making (MCDM) model that enables to match the decision maker's preferences. Classical MCDM methods suppose to conduct an evaluation of some alternatives regarding some criteria, by using qualitative or quantitative scales, crisp or fuzzy values, and direct or comparison-based evaluations. Our goal in this paper is to propose one or more adequate PRM methods to the decision-maker, which supposes to combine screening and ranking. Some evaluations are based on facts and are quantitative, and some are based on human judgment and may be qualitative or fuzzy. Thesubsection 2.1 introduces general MCDM problems and methods. It consists in describing the possible objectives, the classical steps of decision-making process, and the classical principles and approaches. We will explain why we decided to use in our research method a combination of screening and ranking, and a combination of qualitative and fuzzy evaluations. This is detailed in the subsection 2.2.

\subsection{Existing objectives and techniques for MCDM problems}

Three main issues exist in MCDM:

- Choice: choose the best alternative. For a basic decision-making problem of choosing one or several best alternatives, it is useful to begin by eliminating those alternatives that do not appear to warrant further attention, which is called screening (Hobbs and Meier 2000). Screening is the process that reduces a set of alternatives to a smaller set of alternatives that (most likely) contains the best one. It supposes to have some elimination thresholds, or intervals, on evaluation scales.

- $\quad$ Ranking: rank all alternatives from best to worst. It supposes to have a global evaluation model for each alternative, taking into account all the considered criteria and their different scales.

- $\quad$ Sorting: sort all alternatives into different pre-ordered groups

In this work, we consider only screening and ranking categories. A MCDM problem follows the serial process of:

- $\quad$ Defining decision objectives,

- Identifying and arranging alternatives, with potential interdependencies,

- Identifying and arranging criteria, with potential interdependencies,

- $\quad$ Evaluating criteria, with weights and thresholds,

- $\quad$ Evaluating alternatives for each criteria and with a global model,

- $\quad$ Screening out alternatives which do not fit to criteria thresholds

- $\quad$ Ranking remaining alternatives according to their individual evaluations and criteria weights

- $\quad$ Making the decision.

Two kinds of evaluations do exist: the values (preferences on consequences) and the weights (preferences on criteria). Basically, they can be evaluated whether directly or indirectly via relative comparison (often pair wise comparison). Moreover, they can be quantitative, or qualitative, or even fuzzy when the degree of precision and reliability is not enough to get crisp qualitative evaluations. For instance, linguistic decision-making uses linguistic expressions on criteria as constraints, and is mainly used for screening. We distinguish lexicographic constraints and disjunctive/conjunctive constraints. In the first case, criteria are ranked in order of relative importance, and all alternatives are examined to assess whether the first criterion is satisfied. For those alternatives which are not screened out, the process goes on to the second criterion, and so on until the last. Disjunctive or conjunctive constraints express conditions involving more than one criterion, and are characterized by the use of « and » and « or $»$ operators.

For the values, the most known and used models are utility theory (Keeney and Raiffa 1976) and outranking (Vincke1992). It consists in a transformation of raw consequence information into preference information which is useful for the decision-maker. Pareto optimality is a well-known concept introduced by the famous scientist (Pareto1971) which takes into account multiple criteria for overall optimality. It is based on the domination concept, 
and is also called efficiency of an alternative. An alternative is non-dominated or efficient if and only if there does not exist any alternative which is better or equal for all criteria, with one strictly superior value for at least one criterion.

For the criteria, it refers to expression of the relative importance of criteria. Two kinds of weights, trade-off weights (TW) and non trade-off weights (NTW) are defined in (Belton and Stewart 2002). For TW, preferences are compared as they are aggregated into a single expression, a phenomenon called compensation. Trade-off weights are essentially used for classical aggregation models, like additive or average-based methods. It enables to study some phenomena like sensitivity analysis (Rios Insua 1990), dominance and potential optimality (Athanassopoulosand Podinovski 1997, Hazen 1986), which consist of changing inputs (values or weights) to look at consequences on outputs. Non Trade-off weights, also called outranking, were introduced in (Roy 1996). An outranking relation is a binary relation $\mathrm{S}$ defined on $\mathrm{A}$, with the interpretation that ASB if there are enough arguments to decide that $\mathrm{A}$ is at least as good as $\mathrm{B}$, while there is no essential reason to refute that statement (Vincke 1992).

In this paper, we do not consider outranking methodologies but our evaluation will be done according to single synthesis criteria principle, using multi-criteria aggregation and Pareto domination principle. Our approach is mainly on a classical multi-criteria decision-making approach, described for instance in (Steuer et al. 1996; Karacapilidis and Pappis 2000) and including three steps as follows.

\subsection{Definition of a three-step structured approach to select PRM methods}

The first step screens out methods due to lack of maturity in the organization. This means that the organization is not able to properly implement such a method, and that it would be too difficult, too risky, too costly or not profitable to try to apply it.

The second step is also a screening of methods which do not fit with decision-makers' preferences. This is a more classical step since it compares the score of the alternatives (the methods) to the expression of decision-makers' preferences (thresholds on criteria). If a method has a score which is lower than the minimum threshold, then it is eliminated.

The third step is the ranking of the remaining methods using decision-makers' preferences in terms of criteria weights. This is also a classical step in decision-making, based on the aggregation of individual performances (one alternative evaluated on one criterion).

\subsection{Originality and difficulty of this decision-making problem}

The main originality of this problem is to screen out alternatives due to alternatives requirements in the first step. Indeed, it is the organization's maturity assessment (not related to methods) that involves to screen out some methods if their requirements are too high for the organization.

The main difficulty of this problem is that is a quite new question for decision-makers to give preferences for a PRM method. Generally, they did not think about it or about the reasons for having this one. This means that the expression of minimum thresholds and weights for choice criteria is difficult for them. The concern with working with incomplete information arises naturally in the context of multi-criteria decision-making models. Most of the methods deal with imprecision in terms of weights, considering the value of each alternative in each criterion is precisely known (Ahn and Park 2008; Dias and Climaco 2000; Hazen 1986; Salo and Hamalainen 2001; Weber 1987). This justifies our choice to deal with precise alternative evaluations and imprecise decision-makers' preferences. In order to deal with this imprecision, the concept of linguistic variables is very useful (Marimin et al. 1998). Fuzzy set theory can be applied to deal with the situation instead of precise mathematical assessments. Much research has been done in handling the linguistic variable since Zadeh (1975) first proposed the concept (Herrera and Herrera-Viedma 2000; Lu et al. 2007; Ma et al. 2007; Xu 2004). Some works were dedicated to the introduction of fuzzy theory in multicriteria decision-making approaches (Chen and Hwang 1992; Carlsson and Fuller 2002; Shamsuzzaman et al. 2003; Mohanty et al. 2005; Kahraman et al. 2006; Ayag and Ozdemir 2009; Giannopoulos and Founti 2010). More precisely, Zhang and Lu (2003) introduced an integrated group decision-making method with fuzzy preference that has been used in different contexts, but particularly in a method selection context (Zhang and $\mathrm{Lu}$ 2009). This justifies our choice to use fuzzy weights in the ranking step after the two filtering steps. 
The second difficulty is that several decision-makers may be involved in the process. For instance, it is possible to get judgments/evaluations from the project manager, project office manager, methodological support manager, risk manager, portfolio manager or project deputy manager (in charge of risk management). We then consider that judgments/evaluations can be asked of $N d$ decision-makers. Three types of assessments are asked of decisionmakers. The methodological choice is thus to combine different types of evaluations and calculation operators which do not have the same degree of precision and the same competence pre-requisites. Our assumption was to keep it simple in terms of inputs and outputs, and directly related to real-life decision-makers. This means that some intermediary calculations, like the closeness coefficient in the third ranking step, may be more sophisticated because the decision-makers will give weights as inputs and will get scores as outputs. They are able to understand the principle of a distance to a best and to a worst solution, even if they are not familiar with the detailed formula. On the contrary, some group aggregations based on individual evaluations have to be simple, because the data are more directly related to users. For instance, the aggregation of organization's maturity assessments is made with a single average, which is not the most sophisticated method, but enables this value to be calculated and understood during the meetings. This justifies why we used different levels of sophistication at each step of our approach.

\section{Building the decision-making model}

This section introduces the list of PRM methods that will be considered as alternatives for selection. The criteria used to screen out and rank these alternatives are introduced. The list of criteria is broken down into two families, based on the characteristics of the organization and the preferences of the decision-makers.

\subsection{The alternative PRM methods}

The PRM methods have been identified with a literature review focused on both a global research (by keywords, by application fields and by knowledge areas) and a local research (for a specific method, a specific company, a specific journal or conference), in order to be as complete as possible. Only a few references were useful to build the main part of the list (Kawakita 1991; Henley and Kumamoto 1992; Gautier et al. 1997; Bowles 1998; Kerzner 1998; Klein and Cork 1998; MIL-STD-1629 1998; Kaplan et al. 1999; Chapman 2001; Riek 2001; Tumer and Stone 2001; Keizer et al. 2002; Smith and Merritt 2002; Chapman and Ward 2003; Stamatelatos 2004; Stone et al. 2004; Shimizu and Noguchi 2005; Kurtoglu and Tumer 2007; PMI 2008).

They are broken down into two categories: the Risk Identification Methods (RIM) and the Risk Analysis Methods (RAM). Indeed, these two steps are the only ones where methods make a real difference, since the risk treatment (or response planning) is basically decision-making (independent from talking about risks or not) and risk monitoring and control consists of the follow-up of the evolution of the situation over time. 32 RIM and 19 RAM are considered for selection. As some of the methods are suitable for both risk identification and risk analysis, they may appear in both lists. Table 1 displays the description of the 32 RIM. The list of RAM is given in Appendix A (Table 10).

Some authors have studied the importance of these two processes on the global performance of the risk management process, and then on the project management process. These works aim to link project success, decision-making performance and information gathering performance. For instance, risk identification performance strongly influences the completeness and reliability of the list of risks that will be further assessed and analyzed, and is dependent on many factors, including managers' experience, information search style, level of education and training (Maytorena et al. 2007). Experience may help increase performance of the identification, and some works have studied how knowledge management or know-how transfer could help increase the global level of experience of the organization (Niwa and Okuma 1982).Risk analysis requires reliable information about the assessment of each individual risk and the relationships between these risks. This assessment is uncertain, since risks are potential events with an inherent lack of experience and/or expertise, which involves using specific methods to deal with this uncertainty (Kangari and Leland 1992; Scott 2007). Moreover, some works are also related to the dependency relationship between two risks, whether to identify or to estimate these dependencies (Keefer 2004; Heal and Kunreuther 2007).

Since PRM methods have numerous characteristics which make them significantly different, some criteria have to be established in order to facilitate their selection. 
Table 1: List of Risk Identification Methods

\begin{tabular}{|c|c|c|}
\hline \# & Complete Name & Description \\
\hline RIM1 & $\begin{array}{l}\text { Preliminary Risk (or Hazard) Analysis } \\
\text { (PRA or PHA) }\end{array}$ & $\begin{array}{l}\text { Identifies the potential dangerous elements, dangerous situations and hazards. Then, identifies } \\
\text { and evaluates situations which could become dangers (with probability) and their consequences } \\
\text { (with gravity). }\end{array}$ \\
\hline RIM2 & $\begin{array}{l}\text { Strengths, Weaknesses, Opportunities } \\
\& \text { Threats (SWOT) }\end{array}$ & $\begin{array}{l}\text { Strategic planning tool based on information gathering and structuring, mainly used in early } \\
\text { phases. }\end{array}$ \\
\hline RIM3 & Scenario analysis & $\begin{array}{l}\text { Process of analyzing possible future events by considering alternative possible outcomes } \\
\text { (scenarios). }\end{array}$ \\
\hline RIM4 & Who What When Where How Why & formation structuring tool used to gather information and risks on a project \\
\hline RIM5 & Probabilistic Risk Analysis (PRA) & stematic and comprehensive method combining ESD, MLD \\
\hline RIM6 & $\begin{array}{l}\text { Failure Mode, Effects (and Criticality) } \\
\text { Analysis (FMEA or FMECA) }\end{array}$ & $\begin{array}{l}\text { Consists of a qualitative analysis of dysfunctions modes followed by a quantitative analysis of } \\
\text { their effects, with probability and gravity. }\end{array}$ \\
\hline RIM7 & $\begin{array}{l}\text { Project Information Failure Analysis } \\
\text { (PIFA) }\end{array}$ & $\begin{array}{l}\text { Uses FMECA applied to the project modeled as an information process (information input, } \\
\text { treatment and transmission). }\end{array}$ \\
\hline RIM8 & Risk Breakdown Structure (RBS) & $\begin{array}{l}\text { The RBS is a "a hierarchically organized depiction of the identified project risks arranged by } \\
\text { risk category" }\end{array}$ \\
\hline RIM9 & $\begin{array}{l}\text { Design Review Based on Failure Mode } \\
\text { (DRBFM) }\end{array}$ & $\begin{array}{l}\text { An improvement of the FMEA which focuses on best practices to be used when modifications } \\
\text { are done to an existing product }\end{array}$ \\
\hline RIM10 & $\begin{array}{l}\text { Function-Failure Design } \text { Method } \\
\text { (FFDM) }\end{array}$ & Mathematical mapping linking a product's functional model to potential failures known a priori. \\
\hline RIM11 & Reliability Block Diagrams (RBD) & $\begin{array}{l}\text { Block diagrams (like fault trees) provide a } \mathrm{g} \\
\text { between different parts of the system. Incorpora }\end{array}$ \\
\hline RIM12 & Master Logic Block Diagram (MLD) & $\begin{array}{l}\text { A hierarchical model which identifies the links from system top objectives to functions and } \\
\text { components }\end{array}$ \\
\hline RIM13 & $\begin{array}{l}\text { Anticipatory Failure Determination } \\
\text { (AFD) }\end{array}$ & $\begin{array}{l}\text { Based on TRIZ starts from the observed failure (as in FTA) and tries to correct the solution by } \\
\text { changing the point of view }\end{array}$ \\
\hline RIM14 & $\begin{array}{lcc}\text { Technical } & \text { Risk } & \text { Assessment } \\
\text { Methodology (TRAM) } & \end{array}$ & $\begin{array}{l}\text { Dedicated to complex technical systems such as aircraft or computer, based on product } \\
\text { decomposition }\end{array}$ \\
\hline RIM15 & $\begin{array}{l}\text { Functional Failure Identification and } \\
\text { Propagation (FFIP) }\end{array}$ & $\begin{array}{l}\text { Estimates potential faults and their propagation under critical event scenarios using behavioral } \\
\text { simulation }\end{array}$ \\
\hline RIM16 & Hazard Operability (HAZOP) & $\begin{array}{l}\text { lentifies the consequences of variance in components parameters. Variances are expressed by } \\
\text { Io, More, Less, Before, After. }\end{array}$ \\
\hline RIM17 & Root causes analysis & $\begin{array}{l}\text { Root cause analysis (RCA) is a class of problem solving methods aimed at identifying the root } \\
\text { causes of problems or events. The practice of RCA is predicated on the belief that problems are } \\
\text { best solved by attempting to correct or eliminate root causes, as opposed to merely addressing } \\
\text { the immediately obvious symptoms. By directing corrective measures at root causes, it is hoped } \\
\text { that the likelihood of problem recurrence will be minimized. }\end{array}$ \\
\hline RIM18 & $\begin{array}{l}\text { Fault Tree Analysis (Failure tree or } \\
\text { Dysfunction tree) or Cause Tree }\end{array}$ & $\begin{array}{l}\text { Determines the conditions which conduct to an event (deductive reasoning). Uses logical } \\
\text { connectors' combination. The cause tree is similar to the failure tree, except that it analyses the } \\
\text { event a posteriori. }\end{array}$ \\
\hline IM19 & ent Tree Analysis (ETA) & \\
\hline M20 & & \\
\hline RIM21 & Event Sequence Diagrams (ESD) & \\
\hline RIM22 & $\begin{array}{l}\text { Defect Detection and Prevention } \\
\text { Process (DDP) }\end{array}$ & $\begin{array}{l}\text { The application of the DDP process involves four steps: 1) Develop the Requirements Matrix, } \\
\text { 2) Develop the Effectiveness Matrix, 3) Optimize the Residual Risk (subject to constraints) and } \\
\text { 4) Iterate with the Project Life Cycle. }\end{array}$ \\
\hline RIM23 & Affinity diagram $(\mathrm{KJ})$ & $\begin{array}{l}\text { The affinity diagram (or KJ for Kawakita Jiro) is used to generate and organize data about past } \\
\text { problems (facts) or future risks (ideas). It consists in recording each idea, then looking for } \\
\text { relations between ideas and finally sorting them into prioritized groups. Once completed, the } \\
\text { affinity diagram may be used to create a cause and effect diagram. }\end{array}$ \\
\hline RIM24 & Peer interviews & $\begin{array}{l}\text { field. They may be } \\
\text { ea. }\end{array}$ \\
\hline RIM25 & Expert judgment, Delphi method & $\begin{array}{l}\text { emi-structured interview based on questionnaires and allowing mixing individual and group } \\
\text { dgment. }\end{array}$ \\
\hline RIM26 & Risk Diagnosing Methodology (RDM) & $\begin{array}{l}\text { Risk identification and management in innovative projects based on semi-structured interviews } \\
\text { and questionnaires }\end{array}$ \\
\hline IM27 & & \\
\hline RIM28 & Diagramming techniques & $\begin{array}{l}\text { diagram is a two-dimensional geometric symbolic representation of information according to } \\
\text { me visualization technique. In project risk management, the symbolic is often related to } \\
\text { ause-effect relationship. }\end{array}$ \\
\hline & & \\
\hline RIM30 & Pareto analysis & $\begin{array}{l}\text { Pareto analysis is a statistical technique in decision making that is used for selection of a limited } \\
\text { number of tasks that produce significant overall effect. It uses the Pareto principle: a large } \\
\text { majority of problems ( } 80 \% \text { ) are produced by a few key causes (20\%). }\end{array}$ \\
\hline RIM31 & Data analysis & $\begin{array}{l}\text { Data analysis is a process of gathering, modeling, and transforming data with the goal of } \\
\text { highlighting useful information, suggesting conclusions, and supporting decision making: } \\
\text { Examples are correlation method, variance analysis or data mining. }\end{array}$ \\
\hline RIM32 & Risk Analytical Structure (RAS) & List of categories and subcategories in which the risks can appear in a typical project \\
\hline
\end{tabular}




\subsection{The selection criteria related to organizational maturity and decision-makers' preferences}

There are many ways of characterizing PRM methods, but the number of factors that most decision-makers can handle simultaneously cannot be higher than 7 to 9 (Miller 1956). As such, it is necessary to break down the complex decision-making problem into more manageable sub-problems. An initial list of criteria hasbeen developed using previous literature review. Namely, it gave information about characteristics of PRM methods and about expressions of decision-makers' preferences in case studies. This list has been updated and validated through interviews with experts, following the process of a classical Delphi study. The principles were identical, except that the panel of experts did not precisely follow the recommendations of a Delphi study. This was justified by the fact that criteria are not universal. For instance, for car selection, the color, the price and the $\mathrm{CO}_{2}$ rejection rate may be acceptable choice criteria. But, depending on who is buying the car, they will not have the same importance, or the same requirements (in terms of acceptance thresholds) or they may even be irrelevant. For instance, the color is more relevant for a family or for a rent-a-car company than for a company fleet. That means that after identification of potential choice criteria, they have to be filtered by the final user. Each list is thus specific to the context where it is used.This process of adaptation of the list to the specific requirements and context of the organization enables some criteria to be removed, renamed or added. For instance, the "specificity" of the method, i.e. its capacity to be implemented in other domains than the one where it had been developed, was initially removed by several interviewees. But after discussion about the differences between risk identification and risk analysis, they decided to keep it as a selection criterion for analysis and not for identification. On the contrary, the "number of characteristics" was initially proposed for both and was removed for analysis. We are following the principles of co-construction through interaction with decision-makers, described by Roy (2010) as the European conception of decision aiding approach.

Finally, the criteria which are considered here in PRM selection are listed below in table 2. Some of these criteria are common to RIM and RAM assessment. Two types of criteria exist:

- 4 criteria $\left(\mathrm{C}_{1}\right.$ to $\left.\mathrm{C}_{4}\right)$ are about adequacy of the method to the organization. An organization must be mature enough to properly implement a method. It is a mandatory requirement and each method thus has a minimum threshold value for each criterion.

- 8 criteria $\left(\mathrm{C}_{5}\right.$ to $\left.\mathrm{C}_{12}\right)$ are about adequacy of the method to the decision-makers' preferences. A method must fit to what decision-makers want. It may be an obligation, expressed by a minimum threshold, and/or a preference, expressed by a weight.

Table 2: List of Selection Criteria

\begin{tabular}{llll}
$\#$ & Criterion & Family & Type of PRM method \\
\hline C1 & Product design maturity & Organizational maturity & RIM and RAM \\
C2 & Project management maturity & Organizational maturity & RIM and RAM \\
C3 & Risk management maturity & Organizational maturity & RIM and RAM \\
C4 & Product innovation level & Organizational maturity & RIM and RAM \\
\hline C5 & Simplicity of use & Decision-maker's' preferences & RIM and RAM \\
C6 & Interaction considerations & Decision-makers' preferences & RIM and RAM \\
C7 & Completeness & Decision-makers' preferences & RIM \\
C8 & Number of characteristics & Decision-makers' preferences & RIM \\
C9 & Types of data & Decision-makers' preferences & RAM \\
C10 & Graphical display & Decision-makers' preferences & RAM \\
C11 & Specificity & Decision-makers' preferences & RAM \\
C12 & Notoriety & Decision-makers' preferences & RAM \\
\hline
\end{tabular}

The Delphi method (Linstone et al. 2002), which was originally developed in the 1950's, is a systematic and interactive method which relies on a panel of independent experts. It is a very flexible tool which leads to a consensus through the collection of experts' opinions on a given issue during successive stages of questionnaire and feedback. Direct confrontation of the experts, whose anonymity is maintained at every stage of the study, is avoided (Okoli and Pawloswki 2004). As mentioned in (Skulmoski et al. 2007), "the Delphi method is well suited as a research instrument when there is incomplete knowledge about a problem or phenomenon". It has proven over the years to be a very popular tool for framework building, forecasting, prioritizing and decision-making. 
The Delphi process is based upon six successive steps:

1 Reviewing the literature to build up an initial draft of the criteria list.

2 Writing the Delphi survey based on this first list.

3 Selecting the panel of experts for the Delphi survey.

4 Conducting the Delphi survey according to the Delphi methodology.

5 Analyzing and discussing the results of the Delphi survey.

6 Refining the selection criteria list using the results of the Delphi survey.

In our case, our prospective panel was constituted of only 5 experts. So we do not argue that our study is a Delphi study, since it is not statistically significant. But, as there is only one project office manager, only one risk manager and only three project managers (since this type of project was quite new in the company), it was preferable to run the enquiry with these few, but relevant, experts. Skulmoski and co-workers (2007) require different aspects for the participants to be selected in the Delphi survey panel :

1 Sufficient knowledge and experience about the survey issues;

2 Capacity, willingness and time to participate;

3 Good communication skills.

The survey was conducted using first electronic mail, then peer-to-peer short interviews (less than one hour). The questionnaire was introduced by a page explaining, as in (Bryant and Abkowitz 2007), the overall purpose and structure of the survey. The questionnaire was divided into two sections, following the two-level temporal dimension (risk identification and risk analysis).

The questions were formulated thanks to a 5-level Likert scale, in order to express the relevance of a given criterion to risk management method selection (from no contribution -1- to essential contribution -5-, leaving the possibility to answer "do not know" and "do not want to answer"). Furthermore, participants could leave commentaries and questions at any moment on any point of the questionnaire in order to generate discussion about it or to suggest other potential criteria.

Finally, the results are introduced in the following tables, considering the global importance given to the criteria according to the phases (table 3) and according to the roles of the respondents (table 4). In this case, a distinction is made between people who are directly involved in the management of the project (project managers), and people who are indirectly involved (project office manager and risk manager for instance). RI is for Risk Identification, RA for Risk Analysis, PM for Project Management, PO for Project Office, AV for Average and SDEV for Standard Deviation.

Table 3: Results of the survey displayed by phase

\begin{tabular}{|c|c|c|c|c|c|c|c|c|c|c|c|c|}
\hline & \multicolumn{6}{|l|}{ RI } & \multicolumn{6}{|l|}{ RA } \\
\hline & \multicolumn{2}{|l|}{ PM } & \multicolumn{2}{|l|}{$\mathrm{PO}$} & \multicolumn{2}{|c|}{ Global } & \multicolumn{2}{|l|}{ PM } & \multicolumn{2}{|l|}{$\mathrm{PO}$} & \multicolumn{2}{|c|}{ Global } \\
\hline & $\mathrm{AV}$ & SDEV & AV & SDEV & $\mathrm{AV}$ & SDEV & AV & SDEV & $\mathrm{AV}$ & SDEV & AV & SDEV \\
\hline $\mathrm{C} 1$ & 3.67 & 0.58 & 4.5 & 0.71 & 4 & 0.71 & 3.67 & 1.53 & 4.5 & 0.71 & 4 & 1.22 \\
\hline $\mathrm{C} 2$ & 4.67 & 0.58 & 3.5 & 0.71 & 4.2 & 0.84 & 4.00 & 1.00 & 4.5 & 0.71 & 4.2 & 0.84 \\
\hline C3 & 4.33 & 0.58 & 5 & 0.00 & 4.6 & 0.55 & 4.67 & 0.58 & 5 & 0.00 & 4.8 & 0.45 \\
\hline $\mathrm{C} 4$ & 3.67 & 1.53 & 3.5 & 0.71 & 3.6 & 1.14 & 4.33 & 0.58 & 3.5 & 0.71 & 4 & 0.71 \\
\hline C5 & 5.00 & 0.00 & 4 & 1.41 & 4.6 & 0.89 & 4.67 & 0.58 & 4.5 & 0.71 & 4.6 & 0.55 \\
\hline C6 & 3.67 & 1.53 & 4.5 & 0.71 & 4 & 1.22 & 4.00 & 1.73 & 5 & 0.00 & 4.4 & 1.34 \\
\hline C7 & 4.00 & 1.00 & 4.5 & 0.71 & 4.2 & 0.84 & 2.67 & 1.15 & 2 & 0.00 & 2.4 & 0.89 \\
\hline $\mathrm{C} 8$ & 3.67 & 0.58 & 4 & 0.00 & 3.8 & 0.45 & 3.67 & 0.58 & 2 & 0.00 & 2.9 & 1.00 \\
\hline C9 & 2.33 & 1.53 & 2.5 & 0.71 & 2.4 & 1.14 & 4.33 & 0.58 & 4.5 & 0.71 & 4.4 & 0.55 \\
\hline $\mathrm{C} 10$ & 3.33 & 1.53 & 1.5 & 0.71 & 2.6 & 1.52 & 4.33 & 0.58 & 4.5 & 0.71 & 4.4 & 0.55 \\
\hline C11 & 1.33 & 0.58 & 1.5 & 0.71 & 1.4 & 0.55 & 2.67 & 1.53 & 4 & 0.00 & 3.2 & 1.30 \\
\hline $\mathrm{C} 12$ & 1.33 & 0.58 & 1.5 & 0.71 & 1.4 & 0.55 & 2.67 & 1.53 & 4 & 1.41 & 3.2 & 1.48 \\
\hline
\end{tabular}


Table 4: Results of the survey displayed by role

\begin{tabular}{|c|c|c|c|c|c|c|c|c|c|c|c|c|}
\hline & \multicolumn{6}{|l|}{$\mathrm{PM}$} & \multicolumn{6}{|l|}{$\mathrm{PO}$} \\
\hline & \multicolumn{2}{|l|}{ RI } & \multicolumn{2}{|l|}{ RA } & \multicolumn{2}{|c|}{ Global } & \multicolumn{2}{|l|}{ RI } & \multicolumn{2}{|l|}{ RA } & \multicolumn{2}{|c|}{ Global } \\
\hline & $\mathrm{AV}$ & SDEV & $\mathrm{AV}$ & SDEV & $\mathrm{AV}$ & SDEV & AV & SDEV & AV & SDEV & $\mathrm{AV}$ & SDEV \\
\hline $\mathrm{C} 1$ & 3.67 & 0.58 & 3.67 & 1.53 & 3.67 & 1.03 & 4.5 & 0.71 & 4.5 & 0.71 & 4.5 & 0.58 \\
\hline $\mathrm{C} 2$ & 4.67 & 0.58 & 4.00 & 1.00 & 4.33 & 0.82 & 3.5 & 0.71 & 4.5 & 0.71 & 4 & 0.82 \\
\hline $\mathrm{C} 3$ & 4.33 & 0.58 & 4.67 & 0.58 & 4.50 & 0.55 & 5 & 0.00 & 5 & 0.00 & 5 & 0.00 \\
\hline $\mathrm{C} 4$ & 3.67 & 1.53 & 4.33 & 0.58 & 4.00 & 1.10 & 3.5 & 0.71 & 3.5 & 0.71 & 3.5 & 0.58 \\
\hline C5 & 5.00 & 0.00 & 4.67 & 0.58 & 4.83 & 0.41 & 4 & 1.41 & 4.5 & 0.71 & 4.25 & 0.96 \\
\hline C6 & 3.67 & 1.53 & 4.00 & 1.73 & 3.83 & 1.47 & 4.5 & 0.71 & 5 & 0.00 & 4.75 & 0.50 \\
\hline C7 & 4.00 & 1.00 & 2.67 & 1.15 & 3.33 & 1.21 & 4.5 & 0.71 & 2 & 0.00 & 3.25 & 1.50 \\
\hline $\mathrm{C} 8$ & 3.67 & 0.58 & 3.67 & 0.58 & 3.67 & 0.52 & 4 & 0.00 & 2 & 0.00 & 3 & 1.15 \\
\hline C9 & 2.33 & 1.53 & 4.33 & 0.58 & 3.33 & 1.51 & 2.5 & 0.71 & 4.5 & 0.71 & 3.5 & 1.29 \\
\hline $\mathrm{C} 10$ & 3.33 & 1.53 & 4.33 & 0.58 & 3.83 & 1.17 & 1.5 & 0.71 & 4.5 & 0.71 & 3 & 1.83 \\
\hline $\mathrm{C} 11$ & 1.33 & 0.58 & 2.67 & 1.53 & 2.00 & 1.26 & 1.5 & 0.71 & 4 & 0.00 & 2.75 & 1.50 \\
\hline $\mathrm{C} 12$ & 1.33 & 0.58 & 2.67 & 1.53 & 2.00 & 1.26 & 1.5 & 0.71 & 4 & 1.41 & 2.75 & 1.71 \\
\hline
\end{tabular}

Some points have been highlighted in the above tables. Criteria with an average value inferior to 3 were candidates for being removed from the list. The analysis in table 3 was refined considering the roles of the respondents (table 4), and the potential differences between experts close to the project and experts with a higher level of perspective. Secondly, particular attention was paid to criteria close to 3 but with a high standard deviation (superior to 1), since that means that there are divergent opinions on them. For instance, criteria 9 to 12 received a score inferior to 3 for inclusion in the Risk Identification criteria list. But, the consensus was more obvious for criteria 9, 11 and 12 and there were significant differences for criterion 10 between PM experts' opinions and PO experts' opinions. Criteria 7 and 8 received scores which were significantly superior to 3 for identification. For the risk analysis phase, they both received higher scores from PM experts than from PO experts. As criterion 7 is significantly inferior to 3 , it is removed. For criterion 8, the fact that people from PO absolutely do not want it in the list (a score of 2 is very low) meant that it had to be removed from the final list, even if the score of PM experts was superior to 3. This acts as a kind of veto.

Initially, the aim was to build a single list for both risk identification and analysis methods. But with the current results, the decision was made to distinguish for each criterion whether it is applicable for risk identification, for risk analysis or for both. Given these results, the decision-makers made a final proposal in order to deliver the version of the list which is presented in table 2 . The consensus was reached during the first round of discussion. 
Each criterion has been defined upon an ordinal scale, with 3 or 5 discrete levels.Indeed, Larichev and co-authors consider that the ordinal information can be elicited with greater confidence (Larichev et al. 1995). Details about the assessment scale of each criterion are given in table 5 hereunder.

Table 5: List of selection criteria with their evaluation scales

\begin{tabular}{|c|c|c|c|c|c|}
\hline \# & Level 1 & Level 2 & Level 3 & Level 4 & Level 5 \\
\hline $\mathrm{C} 1$ & $\begin{array}{l}\text { Definition of requirements in a } \\
\text { non systematic way, definition of } \\
\text { a product sketch, structures and } \\
\text { drawings. Use of CAD, product } \\
\text { requirements, analysis of life } \\
\text { cycle analysis, process macro } \\
\text { planning, talks with suppliers. } \\
\text { Adoption of simple approval of } \\
\text { phases (gates). }\end{array}$ & $\begin{array}{l}\text { Use of functional modeling, } \\
\text { definition of solution principle, DFx, } \\
\text { alternative conceptions, application } \\
\text { of QFD. Application of FMEA, } \\
\text { CAE, integration supply chain and } \\
\text { specification of the production } \\
\text { process and assembly, use of CAPP } \\
\text { and PDM. }\end{array}$ & $\begin{array}{l}\text { There are } \\
\text { performance } \\
\text { indicators of all } \\
\text { activities. }\end{array}$ & $\begin{array}{l}\text { Control of all activities } \\
\text { with a base in the } \\
\text { indicators and actions } \\
\text { is integrated into the } \\
\text { processes of the } \\
\text { changes management } \\
\text { and incremental } \\
\text { improvement. }\end{array}$ & $\begin{array}{l}\text { Transformation } \\
\text { cycle of the PD } \\
\text { process integrated } \\
\text { into the cycle of } \\
\text { incremental } \\
\text { improvement, the } \\
\text { change } \\
\text { management and } \\
\text { the project } \\
\text { planning. }\end{array}$ \\
\hline $\mathrm{C} 2$ & $\begin{array}{l}\text { No PM processes or practices are } \\
\text { consistently available. No PM } \\
\text { data are consistently collected or } \\
\text { analyzed. Functionally isolated. } \\
\text { Lack of senior management } \\
\text { support. Project success depends } \\
\text { on individual efforts. }\end{array}$ & $\begin{array}{l}\text { Individual project planning. } \\
\text { Informal PM processes are defined. } \\
\text { Informal PM problems are } \\
\text { identified. Informal PM data are } \\
\text { collected. Organizations possess } \\
\text { strengths in doing similar work. }\end{array}$ & $\begin{array}{l}\text { Systematic and } \\
\text { structured } \\
\text { project planning } \\
\text { and control for } \\
\text { individual } \\
\text { projects. } \\
\text { Informal training } \\
\text { of PM skills and } \\
\text { practices. }\end{array}$ & $\begin{array}{l}\text { Strong teamwork. } \\
\text { Formal PM training for } \\
\text { project team. Planning } \\
\text { and controlling } \\
\text { multiple projects in a } \\
\text { professional matter. } \\
\text { Integrated } \quad \text { PM } \\
\text { processes. Data are } \\
\text { quantitatively analyzed, } \\
\text { measured and stored. }\end{array}$ & $\begin{array}{l}\text { Project-driven } \\
\text { organization. } \\
\text { Dynamic, energetic, } \\
\text { and fluid } \\
\text { organization. } \\
\text { Continuous } \\
\text { improvement of } \\
\text { PM. }\end{array}$ \\
\hline
\end{tabular}

\begin{tabular}{|c|c|c|c|}
\hline$\#$ & Level 1 & Level 2 & Level 3 \\
\hline $\mathrm{C} 4$ & $\begin{array}{l}\text { Low maturity team without whether no expertise } \\
\text { or experience in project risk management. } \\
\text { Alternative }\end{array}$ & $\begin{array}{l}\text { Mature and experimented team with expertise } \\
\text { and experience on project risk management. } \\
\text { Adaptive }\end{array}$ & $\begin{array}{l}\text { Very mature team, with adaptability } \\
\text { and resilience to unknown situations. } \\
\text { Innovative }\end{array}$ \\
\hline C5 & $\begin{array}{l}\text { The method is valid only in the context where it } \\
\text { has been created. }\end{array}$ & $\begin{array}{l}\text { The method is valid only on some contexts, like } \\
\text { a type of project or an industrial sector. }\end{array}$ & $\begin{array}{l}\text { The method is quite generic and } \\
\text { applicable to every project. }\end{array}$ \\
\hline C6 & Risks are considered and managed as independent & $\begin{array}{l}\text { Risks are interrelated with simple cause-effect } \\
\text { links or trees }\end{array}$ & $\begin{array}{l}\text { Risks are interrelated with complex } \\
\text { cause-effect links, including } \\
\text { reciprocal links and loops }\end{array}$ \\
\hline $\mathrm{C} 7$ & $\begin{array}{l}\text { The method enables to identify some specific } \\
\text { risks and does not cover the whole areas of } \\
\text { project risks. }\end{array}$ & $\begin{array}{l}\text { The method intends to cover the different areas, } \\
\text { but without a certainty about the completeness } \\
\text { (in the defined scope). }\end{array}$ & $\begin{array}{l}\text { The method enables to obtain a quite } \\
\text { good completeness, in the considered } \\
\text { scope. }\end{array}$ \\
\hline $\mathrm{C} 8$ & $\begin{array}{l}\text { Only basic information, like name, nature, } \\
\text { probability (or likelihood) and impact (or gravity) } \\
\text { are managed. }\end{array}$ & $\begin{array}{l}\text { Some intermediary concepts are manipulated, } \\
\text { like direct causes and effects, mode of failure. }\end{array}$ & $\begin{array}{l}\text { Some advanced concepts are } \\
\text { manipulated, like detection ability, } \\
\text { vulnerability or level of influence. }\end{array}$ \\
\hline C9 & $\begin{array}{l}\text { Manipulation on qualitative and subjective data } \\
\text { only. }\end{array}$ & $\begin{array}{l}\text { Manipulation on both qualitative and } \\
\text { quantitative data. Qualitative data can even be } \\
\text { fuzzy. Even qualitative data may be based on } \\
\text { experience. }\end{array}$ & $\begin{array}{l}\text { Manipulation on quantitative and } \\
\text { reliable data issued from previous } \\
\text { experience, potentially with } \\
\text { statistical analysis. }\end{array}$ \\
\hline $\mathrm{C} 10$ & $\begin{array}{l}\text { The method is not easy to understand, even for } \\
\text { specialists of risk management, and takes a long } \\
\text { time to be appropriated, especially for users (non } \\
\text { specialists). }\end{array}$ & $\begin{array}{l}\text { The method requires some time and explanations } \\
\text { to be understood and appropriated, but remains } \\
\text { easy to use. }\end{array}$ & $\begin{array}{l}\text { The method is easy and fast to } \\
\text { understand. No pre-requisite. The } \\
\text { appropriation time is low. }\end{array}$ \\
\hline $\mathrm{C} 11$ & $\begin{array}{l}\text { The method is unknown, except where it is used } \\
\text { and where it has been developed. }\end{array}$ & $\begin{array}{l}\text { The method is known by some specialists, } \\
\text { experts and companies. }\end{array}$ & $\begin{array}{l}\text { The method is well-known by almost } \\
\text { every people involved in project risk } \\
\text { management. }\end{array}$ \\
\hline $\mathrm{C} 12$ & No graphs, only lists or tables & $\begin{array}{l}\text { Basic graphs, like Farmer diagram, Kiviat } \\
\text { diagram or color tables (for criticality areas for } \\
\text { instance) }\end{array}$ & $\begin{array}{l}\text { Advanced graphs, like cause-effect } \\
\text { trees or networks, with or without } \\
\text { logical gates and with or without } \\
\text { loops. }\end{array}$ \\
\hline
\end{tabular}

In the next sections, the criteria will be used for screening out methods which do not correspond to minimum thresholds (Section 4 and Section 5). Then, remaining alternatives will be ranked using criteria weights and methods evaluations (Section 6). 


\section{Screening out inadequate methods regarding organizational maturity (criteria $C_{1}$ to $C_{4}$ )}

The first filtering step is original in terms of decision-making, since it does not depend on the decision-maker, but on the alternatives requirements. The maturity of the organization is assessed, and then compared with the requirements of the PRM methods in terms of minimal thresholds. This enables methods which are too difficult to implement to be screened out.

4.1. Assessing the minimum maturity that the organization must have in order to be able to implement a PRM method

We define the index $i$ of each PRM method as following.

$\mathrm{PRM}_{\mathrm{i}}=\mathrm{RIM}_{\mathrm{i}}$ for $\mathrm{i}=1$ to 32 and $\mathrm{PRM}_{\mathrm{i}}=\mathrm{RAM}_{\mathrm{i}-32}$ for $\mathrm{i}=33$ to 51

This enablesa score to be given to all the methods using a single index. For organizational maturity criteria $(j=1$ to 4), the minimum value that the organization must have on the $\mathrm{j}^{\text {th }}$ criterion in order to be able to properly implement the $\mathrm{i}^{\text {th }}$ method is assessed. This is a Minimum Threshold, not a preference, and is thus called $\mathrm{MT}_{\mathrm{ij}}=\mathrm{MT}\left(\mathrm{PRM}_{\mathrm{i}}, \mathrm{C}_{\mathrm{j}}\right)$. Table 6 displays these $\mathrm{MT}_{\mathrm{ij}}$, with RIM (on the top) and RAM (on the bottom part of the table).

\subsection{The assessment by the decision-makers of their own organization}

For each $\mathrm{k}=1$ to $\mathrm{Nd}$, these assessments are made by the $\mathrm{k}^{\text {th }}$ decision-maker and are called $\left(\mathrm{O}_{\mathrm{j}}^{\mathrm{k}}\right)_{\mathrm{j}=1}$ to 4 . As several opinions are given, there may be differences and even inconsistency that will need to be managed. For the assessment of the organization's maturity, as explained in Section 2, a single average is calculated as shown in equation (1), in order to get immediately a group assessment from individual assessments:

$O_{j}=\frac{1}{N d} \sum_{k=1}^{N d} O_{j}^{k}$

\subsection{Adequacy of the organization to the methods}

The assessment of the organization $\mathrm{O}_{\mathrm{j}}$ of section 4.2 is compared to the Minimum Threshold $\left(\mathrm{MT}_{\mathrm{ij}}\right)_{\mathrm{i}} \mathrm{i}=1$ to $32, \mathrm{j}=1$ to 4 introduced in section 4.1. If a method has a threshold which is higher than an organization's assessment, then it is removed since it is too difficult to implement and inappropriate to the organization's situation. This is expressed in equation (2) with a score for the $\mathrm{i}^{\text {th }} \mathrm{PRM}$, called $\mathrm{S}\left(\mathrm{PRM} \mathrm{M}_{\mathrm{i}}\right)$, where the method is screened out if its score is equal to zero:

for $j \in\{1 . .4\}$, for $i \in\{1 . .51\}$, if $O_{j}<M T_{i j}$ then $S\left(P R M_{i}\right)=0$, else $S\left(P R M_{i}\right)=1$ 
Table 6: assessment of minimum thresholds for RIM and RAM on the organizational criteria $\left(\mathrm{C}_{1}\right.$ to $\left.\mathrm{C}_{4}\right)$

\begin{tabular}{|c|c|c|c|c|c|c|c|c|c|c|c|}
\hline $\begin{array}{l}\text { PRM } \\
\text { index }\end{array}$ & $\begin{array}{l}\text { RIM } \\
\text { index }\end{array}$ & $\begin{array}{l}\text { Product } \\
\text { design } \\
\text { maturity } \\
\text { (C1) }\end{array}$ & $\begin{array}{l}\text { Project } \\
\text { managemen } \\
\text { t maturity } \\
\text { (C2) } \\
\end{array}$ & $\begin{array}{l}\text { Risk } \\
\text { managemen } \\
\text { t maturity } \\
\text { (C3) }\end{array}$ & $\begin{array}{l}\text { Product } \\
\text { innovati } \\
\text { on level } \\
\text { (C4) }\end{array}$ & $\begin{array}{l}\text { PRM } \\
\text { index } \\
\end{array}$ & $\begin{array}{l}\text { RIM } \\
\text { index }\end{array}$ & $\begin{array}{l}\text { Product } \\
\text { design } \\
\text { maturity } \\
\text { (C1) }\end{array}$ & $\begin{array}{l}\text { Project } \\
\text { managemen } \\
\mathrm{t} \text { maturity } \\
\text { (C2) } \\
\end{array}$ & $\begin{array}{l}\text { Risk } \\
\text { managemen } \\
\text { t maturity } \\
\text { (C3) } \\
\end{array}$ & $\begin{array}{l}\text { Product } \\
\text { innovatio } \\
\mathrm{n} \text { level } \\
\text { (C4) }\end{array}$ \\
\hline PRM1 & RIM1 & 1 & 1 & 1 & 1 & PRM17 & RIM17 & 3 & 3 & 3 & 3 \\
\hline PRM2 & RIM2 & 1 & 1 & 1 & 1 & PRM18 & RIM18 & 3 & 3 & 1 & 1 \\
\hline PRM3 & RIM3 & 1 & 1 & 1 & 1 & PRM19 & RIM19 & 3 & 3 & 3 & 3 \\
\hline PRM4 & RIM4 & 3 & 3 & 3 & 3 & PRM20 & RIM20 & 1 & 1 & 2 & 2 \\
\hline PRM5 & RIM5 & 3 & 3 & 3 & 3 & PRM21 & RIM21 & 3 & 3 & 3 & 3 \\
\hline PRM6 & RIM6 & 3 & 3 & 3 & 3 & PRM22 & RIM22 & 3 & 3 & 3 & 3 \\
\hline PRM7 & RIM7 & 3 & 3 & 3 & 3 & PRM23 & RIM23 & 1 & 1 & 2 & 2 \\
\hline PRM8 & RIM8 & 3 & 3 & 3 & 3 & PRM24 & RIM24 & 1 & 1 & 2 & 2 \\
\hline PRM9 & RIM9 & 3 & 3 & 1 & 1 & PRM25 & RIM25 & 1 & 1 & 2 & 2 \\
\hline PRM10 & RIM10 & 3 & 3 & 3 & 3 & PRM26 & RIM26 & 1 & 1 & 2 & 2 \\
\hline PRM11 & RIM11 & 3 & 3 & 1 & 1 & PRM27 & RIM27 & 1 & 1 & 2 & 2 \\
\hline PRM12 & RIM12 & 3 & 3 & 3 & 3 & PRM28 & RIM28 & 1 & 1 & 1 & 1 \\
\hline PRM13 & RIM13 & 3 & 3 & 3 & 3 & PRM29 & RIM29 & 3 & 3 & 1 & 1 \\
\hline PRM14 & RIM14 & 3 & 3 & 3 & 3 & PRM30 & RIM30 & 3 & 3 & 1 & 1 \\
\hline PRM15 & RIM15 & 3 & 3 & 3 & 3 & PRM31 & RIM31 & 3 & 3 & 1 & 1 \\
\hline PRM16 & RIM16 & 3 & 3 & 3 & 3 & PRM32 & RIM32 & 3 & 3 & 1 & 1 \\
\hline
\end{tabular}

\begin{tabular}{|c|c|c|c|c|c|}
\hline PRM index & RAM index & $\begin{array}{l}\text { Product } \\
\text { design } \\
\text { maturity } \\
\text { (C1) }\end{array}$ & $\begin{array}{l}\text { Project } \\
\text { management } \\
\text { maturity } \\
\text { (C2) }\end{array}$ & $\begin{array}{l}\text { Risk } \\
\text { management } \\
\text { maturity } \\
\text { (C3) }\end{array}$ & $\begin{array}{l}\text { Product } \\
\text { innovation level } \\
\text { (C4) }\end{array}$ \\
\hline PRM33 & RAM1 & 3 & 3 & 3 & 3 \\
\hline PRM34 & RAM2 & 3 & 3 & 1 & 1 \\
\hline PRM35 & RAM3 & 3 & 3 & 1 & 1 \\
\hline PRM36 & RAM4 & 3 & 3 & 3 & 3 \\
\hline PRM37 & RAM5 & 3 & 3 & 3 & 3 \\
\hline PRM38 & RAM6 & 3 & 3 & 3 & 3 \\
\hline PRM39 & RAM7 & 3 & 3 & 1 & 1 \\
\hline PRM40 & RAM8 & 1 & 1 & 1 & 1 \\
\hline PRM41 & RAM9 & 1 & 1 & 1 & 1 \\
\hline PRM42 & RAM10 & 3 & 3 & 3 & 3 \\
\hline PRM43 & RAM11 & 3 & 3 & 1 & 1 \\
\hline PRM44 & RAM12 & 1 & 1 & 2 & 2 \\
\hline PRM45 & RAM13 & 1 & 1 & 2 & 2 \\
\hline PRM46 & RAM14 & 1 & 1 & 2 & 2 \\
\hline PRM47 & RAM15 & 1 & 1 & 2 & 2 \\
\hline PRM48 & RAM16 & 1 & 1 & 2 & 2 \\
\hline PRM49 & RAM17 & 3 & 3 & 3 & 3 \\
\hline PRM50 & RAM18 & 1 & 1 & 1 & 1 \\
\hline PRM51 & RAM19 & 3 & 3 & 3 & 3 \\
\hline
\end{tabular}




\section{Screening out inadequate methods regarding decision-makers preferences (criteria $C_{5}$ to $C_{12}$ )}

This second filter is more classical, since alternatives are screened out if they do not fit with minimal requirements of decision-makers.

\subsection{Assessing the score of the PRM methods on the preference criteria}

For preference criteria ( $\mathrm{j}=5$ to 12 ), the assessment of PRM methods is the score that the $\mathrm{i}^{\text {th }}$ method has in the considered scale of the $\mathrm{j}^{\text {th }}$ criterion. This is known as $\mathrm{S}_{\mathrm{ij}}=\mathrm{S}\left(\mathrm{PRM}_{\mathrm{i}}, \mathrm{C}_{\mathrm{j}}\right)$. Table 7 displays these $\mathrm{S}_{\mathrm{ij}}$, with both RIM (in the top half) and RAM (in the bottom half).It has to be noted that tables 6 and 7 assess values with completely different meanings, although they look very similar.

5.2. Assessing the minimum score that a method must have in order to fit with decision-makers' requirements

These thresholds, called $\mathrm{MT}_{\mathrm{j}}^{\mathrm{k}}, \mathrm{j}=1$ to 4 for the $\mathrm{k}^{\text {th }}$ decision-maker, are expressed as discrete values on the evaluation scale of the $\mathrm{j}^{\text {th }}$ criterion. As the lowest value is 1 , if there is no minimum threshold expressed by the decision-maker, then $\mathrm{MT}_{\mathrm{j}}{ }^{\mathrm{k}}$ is equal to 1 . When considering multiple decision-makers, the rule of the hardest opinion is applied. It considers that the method must fit with the minimum thresholds of all the decision-makers, as expressed in equation (3):

$M T_{j}=\min _{k} M T_{j}^{k}$

This may have a significant impact on the existence or not of a feasible solution, since the group opinion is the hardest and has the tightest constraints.

\subsection{Adequacy of methods to decision-makers' preferences}

The minimum threshold expressed by decisions-makers on the $\mathrm{j}^{\text {th }}$ criterion $\mathrm{MT}_{\mathrm{j}}$ is compared to the score of the $\mathrm{i}^{\text {th }}$ method $\mathrm{S}_{\mathrm{ij}}$. If $\mathrm{PRM}_{\mathrm{i}}$ has an evaluation on the $\mathrm{j}^{\text {th }}$ criterion which is strictly lower than this threshold, then it is removed, as expressed in equation (4).

for $j \in\{5 . .12\}$, for $i \in\{1 . .51\}$, if $S_{i j}<M T_{j}$ then $S\left(P R M_{i}\right)=0$, else $S\left(P R M_{i}\right)=1$ 
Table 7: Assessment of RIM and RAM on Preference Criteria $\left(\mathrm{C}_{5}\right.$ to $\left.\mathrm{C}_{12}\right)$

\begin{tabular}{|c|c|c|c|c|c|c|c|c|c|c|c|}
\hline $\begin{array}{l}\text { PRM } \\
\text { index }\end{array}$ & $\begin{array}{l}\text { RIM } \\
\text { index }\end{array}$ & $\begin{array}{l}\text { Simplici } \\
\text { ty of use } \\
\text { (C5) }\end{array}$ & $\begin{array}{l}\text { Interacti } \\
\text { on } \\
\text { consider } \\
\text { ations } \\
\text { (C6) }\end{array}$ & $\begin{array}{l}\text { Completen } \\
\text { ess } \\
\text { (C7) } \\
\end{array}$ & $\begin{array}{l}\text { Number of } \\
\text { characteristi } \\
\text { cs } \\
\text { (C8) }\end{array}$ & $\begin{array}{l}\text { PRM } \\
\text { index }\end{array}$ & $\begin{array}{l}\text { RIM } \\
\text { index }\end{array}$ & $\begin{array}{l}\text { Simpli } \\
\text { city of } \\
\text { use } \\
\text { (C5) }\end{array}$ & $\begin{array}{l}\text { Interaction } \\
\text { considerati } \\
\text { ons } \\
\text { (C6) }\end{array}$ & $\begin{array}{l}\text { Complet } \\
\text { eness } \\
\text { (C7) }\end{array}$ & $\begin{array}{l}\text { Number of } \\
\text { characterist } \\
\text { ics } \\
\text { (C8) }\end{array}$ \\
\hline PRM1 & RIM1 & 1 & 2 & 3 & 2 & PRM17 & RIM17 & 3 & 2 & 2 & 1 \\
\hline PRM2 & RIM2 & 2 & 1 & 2 & 1 & PRM18 & RIM18 & 2 & 2 & 2 & 1 \\
\hline PRM3 & RIM3 & 2 & 2 & 2 & 2 & PRM19 & RIM19 & 2 & 2 & 2 & 1 \\
\hline PRM4 & RIM4 & 3 & 1 & 1 & 1 & PRM20 & RIM20 & 3 & 2 & 3 & 1 \\
\hline PRM5 & RIM5 & 2 & 2 & 3 & 3 & PRM21 & RIM21 & 1 & 3 & 3 & 3 \\
\hline PRM6 & RIM6 & 2 & 2 & 3 & 3 & PRM22 & RIM22 & 1 & 2 & 3 & 3 \\
\hline PRM7 & RIM7 & 2 & 1 & 3 & 3 & PRM23 & RIM23 & 1 & 2 & 3 & 3 \\
\hline PRM8 & RIM8 & 3 & 1 & 3 & 1 & PRM24 & RIM24 & 3 & 1 & 2 & 2 \\
\hline PRM9 & RIM9 & 2 & 1 & 3 & 3 & PRM25 & RIM25 & 2 & 2 & 3 & 3 \\
\hline PRM10 & RIM10 & 1 & 2 & 2 & 2 & PRM26 & RIM26 & 2 & 1 & 2 & 1 \\
\hline PRM11 & RIM11 & 1 & 3 & 2 & 2 & PRM27 & RIM27 & 3 & 2 & 2 & 2 \\
\hline PRM12 & RIM12 & 1 & 3 & 3 & 3 & PRM28 & RIM28 & 1 & 3 & 3 & 1 \\
\hline PRM13 & RIM13 & 1 & 2 & 3 & 3 & PRM29 & RIM29 & 3 & 2 & 3 & 2 \\
\hline PRM14 & RIM14 & 1 & 2 & 3 & 3 & PRM30 & RIM30 & 3 & 1 & 2 & 1 \\
\hline PRM15 & RIM15 & 1 & 3 & 3 & 3 & PRM31 & RIM31 & 1 & 1 & 3 & 3 \\
\hline PRM16 & RIM16 & 1 & 2 & 2 & 1 & PRM32 & RIM32 & 3 & 1 & 3 & 1 \\
\hline
\end{tabular}

\begin{tabular}{|c|c|c|c|c|c|c|c|}
\hline $\begin{array}{l}\text { PRM } \\
\text { index }\end{array}$ & $\begin{array}{l}\text { RAM } \\
\text { index }\end{array}$ & $\begin{array}{l}\text { Simpli } \\
\text { city of } \\
\text { use } \\
\text { (C5) }\end{array}$ & $\begin{array}{l}\text { Interaction } \\
\text { considerati } \\
\text { ons } \\
\text { (C6) }\end{array}$ & $\begin{array}{l}\text { Types of } \\
\text { data } \\
\text { (C9) }\end{array}$ & $\begin{array}{l}\text { Graphic } \\
\text { al } \\
\text { display } \\
(\mathrm{C} 10)\end{array}$ & $\begin{array}{l}\text { Notoriet } \\
\mathrm{y} \\
\text { (C11) }\end{array}$ & $\begin{array}{l}\text { Specificity } \\
\text { (C12) }\end{array}$ \\
\hline PRM33 & RAM1 & 3 & 2 & 1 & 1 & 3 & 3 \\
\hline PRM34 & RAM2 & 2 & 2 & 1 & 1 & 3 & 3 \\
\hline PRM35 & RAM3 & 2 & 2 & 3 & 3 & 3 & 3 \\
\hline PRM36 & RAM4 & 3 & 1 & 1 & 1 & 1 & 2 \\
\hline PRM37 & RAM5 & 3 & 2 & 3 & 3 & 3 & 3 \\
\hline PRM38 & RAM6 & 2 & 2 & 2 & 1 & 2 & 2 \\
\hline PRM39 & RAM7 & 2 & 2 & 3 & 3 & 2 & 3 \\
\hline PRM40 & RAM8 & 1 & 3 & 3 & 2 & 2 & 2 \\
\hline PRM41 & RAM9 & 2 & 2 & 3 & 3 & 2 & 2 \\
\hline PRM42 & RAM10 & 1 & 2 & 1 & 1 & 1 & 1 \\
\hline PRM43 & RAM11 & 1 & 1 & 1 & 1 & 1 & 1 \\
\hline PRM44 & RAM12 & 1 & 2 & 3 & 3 & 2 & 3 \\
\hline PRM45 & RAM13 & 2 & 1 & 3 & 3 & 1 & 1 \\
\hline PRM46 & RAM14 & 1 & 1 & 3 & 1 & 2 & 2 \\
\hline PRM47 & RAM15 & 1 & 2 & 3 & 2 & 1 & 3 \\
\hline PRM48 & RAM16 & 3 & 2 & 1 & 1 & 1 & 3 \\
\hline PRM49 & RAM17 & 2 & 1 & 1 & 2 & 1 & 2 \\
\hline PRM50 & RAM18 & 1 & 2 & 3 & 2 & 1 & 2 \\
\hline PRM51 & RAM19 & 2 & 2 & 1 & 1 & 1 & 2 \\
\hline
\end{tabular}




\section{Ranking remaining methods regarding decision-makers' preferences (criteria $C_{5}$ to $C_{12}$ )}

PRM methods alternatives have been filtered in sections 4 and 5. Remaining alternatives are now ranked, using a fuzzy weighted average and the calculation of a distance to respectively the best and the worst (but feasible) solutions.

\subsection{The assessment of the importance of each criterion expressed as a fuzzy weight}

Preferences are often uncertain and expressed in linguistic terms, such as "good", "very much", "I prefer", which may require the use of fuzzy set theory. The use of fuzzy weight is justified here by the uncertainty inherent in the expression of a preference by decision-makers. Basic definitions and principles of fuzzy sets are introduced in Appendix B.Six levels are introduced in a linguistic scale to represent the importance of the criterion: "Negligible $(\mathrm{N})$, Very Low (VL), Low (L), Average (A), High (H) and Very High (VH)". Each level is expressed with a fuzzy number as shown in Figure 1. Finally, for the $\mathrm{j}^{\text {th }}$ criterion and the $\mathrm{k}^{\text {th }}$ decision-maker, the fuzzy weight $\mathrm{FW}_{\mathrm{j}} \mathrm{k}_{\mathrm{i}}$ calculated.

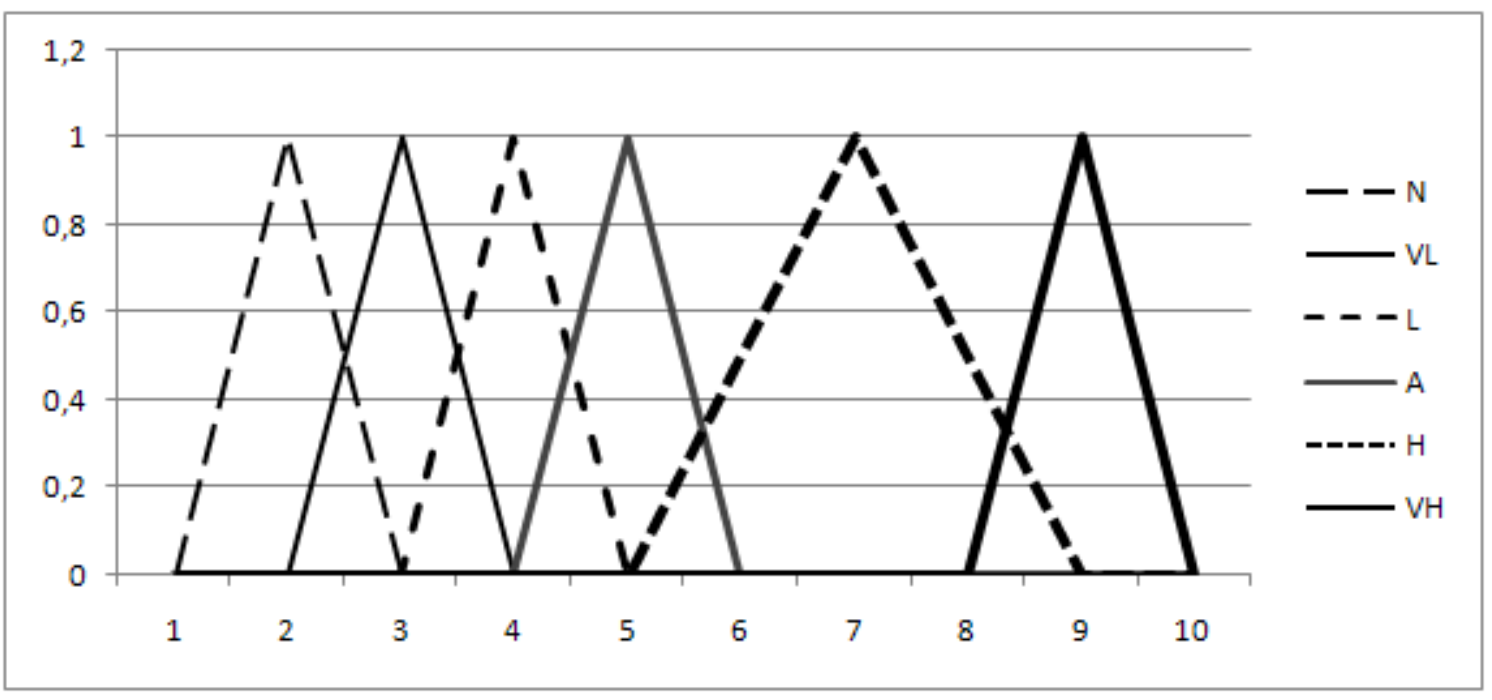

Figure 1: Description of the fuzzy numbers associated with linguistic expressions of weights

The aggregated fuzzy weight is obtained by a fuzzy average, which gives a new fuzzy set for each criterion, as shown in equation (5):

$F W_{j}=\frac{1}{N d}\left(F W_{j}^{1} \oplus F W_{j}^{2} \oplus \ldots \oplus F W_{j}^{N d}\right)$

Where $\oplus^{\oplus}$ represents the fuzzy addition as defined in Appendix B. 


\subsection{Ranking using fuzzy weights}

An aggregated score is proposed in equation (6) for each remaining PRM method, considering for each criterion $\mathrm{C}_{\mathrm{j}}$ the evaluation $\mathrm{S}_{\mathrm{ij}}$ introduced in section 5.1 and the fuzzy weight $\mathrm{FW}_{\mathrm{j}}$ introduced in section 6.1.

$$
S_{i}=S\left(P R M_{i}\right)=\frac{\Sigma_{j} F W_{j} * S_{i j}}{\sum_{j} F W_{j}}
$$

This operation is referred to as a fuzzy weighted average (FWA). Several works use this method to determine a global fuzzy score (Bass and Kwakernaak 1977; Schmucker 1984; Wirba, Tah et al. 1996; Tah and Carr 2000).

A distance is introduced with the following definition (equation 7):

$$
d(x, y)=\left(\int_{0}^{1} \frac{1}{2}\left[\left(x_{\lambda}^{L}-y_{\lambda}^{L}\right)^{2}+\left(x_{\lambda}^{R}-y_{\lambda}^{R}\right)^{2}\right] d \lambda\right)^{1 / 2}
$$

Where $a_{\lambda}^{L}$ and $x_{\lambda}^{R}$ are respectively the left bound and the right bound of the $\lambda$-cut of the fuzzy set.

Zhang and $\mathrm{Lu}$ introduce the concept of closeness coefficient which is similar to the Topsis method (Zhang and Lu 2009). It consists in defining two fictive alternatives and measuring the distance of the $\mathrm{i}^{\text {th }}$ method from these reference points. $\mathrm{PRM}^{\mathrm{max}}$ is the fictive method which has the highest score for each criterion. $\mathrm{PRM}^{\mathrm{min}}$ is the fictive method which has the minimal score for each criterion, considering that it should be at least equal to the expressed minimum thresholds. That means that $\mathrm{PRM}^{\mathrm{min}}$ is a feasible even if fictive alternative. The two distances are defined below:

$\mathrm{d}_{\mathrm{i}}^{\text {max }}=\mathrm{d}\left(\mathrm{PRM}_{\mathrm{i}}, \mathrm{PRM}^{\mathrm{max}}\right)$ and $\mathrm{d}_{\mathrm{i}}^{\text {min }}=\mathrm{d}\left(\mathrm{PRM}_{\mathrm{i}}, \mathrm{PRM}^{\mathrm{min}}\right)$

Finally, the closeness coefficient is defined in equation 8 , the aim being to minimize it:

$$
C C_{i}=\frac{1}{2}\left(d_{i}^{\max }+\left(1-d_{i}^{\min }\right)\right)
$$

\subsection{Refining the results using additional parameters}

The final choice may be made very quickly by selecting the first method in each ranking. There will be a RIM and a RAM with the lowest closeness coefficient. Below, we give three suggestions for refining this initial choice.

\subsubsection{The significance of the gaps in the ranking}

The reliability of the outputs depends on the reliability of the inputs. We argue that there should be a large enough gap between two alternatives to decide with sufficient reliabilitywhich one to choose, and which to reject. If maximal fuzzy score of solution A is inferior to minimal fuzzy score of solution B, then we can be confident on the choice of $\mathrm{B}$ and the elimination of A. At the beginning of the process, the decision-maker can set up a minimal gap MG between two solutions.

If $\mathrm{CC}_{\mathrm{i} 1}>\mathrm{CC}_{\mathrm{i} 2}+\mathrm{MG}$, then the choice of $\mathrm{PRM}_{\mathrm{i} 1}$ is considered as reliable enough.

If solutions are still too close for a decision to be made, a difference can be made with the compatibility parameter described below. 


\subsubsection{The choice of a combination of (RIM+RAM) instead of two independent choices}

We introduce CR as the Compatibility Ratio between two methods, respectively one RIM and one RAM. We define the score of a couple of $\mathrm{RIM}_{\mathrm{i} 0}$ and $\mathrm{RAM}_{\mathrm{i} 1}$ as follows:

$$
\mathrm{CC}\left(\mathrm{RIM}_{\mathrm{i} 0}, \mathrm{RAM}_{\mathrm{i} 1}\right)=\mathrm{CC}_{\mathrm{i} 0} * \mathrm{CC}_{\mathrm{i} 1} * \mathrm{CR}\left(\mathrm{RIM}_{\mathrm{i} 0}, \mathrm{RAM}_{\mathrm{i} 1}\right)
$$

CR is equal to 1 when methods are independent or neutral, and is superior to 1 if methods fit easily. For instance, FMEA (Failure Mode and Effects Analysis) can be used both as a RIM or a RAM, then its CR is superior to 1. Brainstorming is a standard RIM that does not have positive or negative influence on the use of RAM, so the CR is equal to 1. On the contrary, the identification of risks using "cause trees" (RIM 18) is not adequate to the analysis of a global risk exposure, like in "Monte-Carlo simulation" (RAM 9) or "Scoring methodology" (RAM 13). These are different ways of thinking and of using data; so CR is inferior to 1 . If these methods remain very close to the two first refinements, a third one is possible by considering the change that is required for the organization to implement each method.

\subsubsection{The organizational cost of implementation of a method}

We introduce IE as the Implementation Effort of a PRM method in the company. This ratio depends on both the method and the organization. It is not a ratio which is independent of the organization. A penalty/bonus can be applied to the initial score of a PRM by multiplying it by this index.

$\mathrm{CC}^{\prime}{ }_{\mathrm{i} 0}=\mathrm{CC}_{\mathrm{i} 0} * \mathrm{IE}_{\mathrm{i} 0}$

These three refinements may be applied simultaneously, independently or not at all.

\section{Numerical application and discussion}

This section introduces an application of this methodology in a real organization.

\subsection{Description of the example and application of the selection procedure}

An application of our structured approach for selection of the PRM method was carried out within a company which delivers tramway infrastructure for cities. The company has historically focused on product development and had recently extended its scope by delivering both the product and its environment to a city, that is to say the civil engineering, the signaling material, the maintenance and storage depots, etc. As this type of project was new for the company, the question of Project Risk Management method was considered appropriate, as risk management for product development is not the same for other areas such as civil work.

The first action consisted in interviewing several persons directly or indirectly involved in the selection of a PRM method. We interviewed people involved in ongoing projects of this type and people assigned to the project office. These participants were given a background questionnaire on their experience in the organization and in these kinds of project. They were given a presentation of the methods, the criteria and the evaluations of the methods according to the criteria. Then, they were asked to answer questions about their organization and about their preferences regarding the selection criteria. To avoid potential differences among interviewers and their interviewing techniques, only one interviewer was used for all the interviews. There was no question in this case about standardization of the method to all projects of this type. The goal was only to test which risk identification and analysis methods could best fit these five specific projects. The smallest project had a 5-year timescale and a budget of $200 \mathrm{M} €$. These interviews gave us information about the maturity and the preferences of the organization. Table 8 shows the average judgment about the four organizational criteria $\mathrm{C}_{1}$ to $\mathrm{C}_{4}$. It introduces three examples of RIM, where two are kept for future steps (RIM 9 and RIM 27) and one is screened out at this stage (RIM 17), since the requirement on criteria 3 and 4 are not fulfilled by the organization. 
Table 8: Decision-Makers' judgments about Organizational Maturity (criteria $\mathrm{C}_{1}$ to $\mathrm{C}_{4}$ )

\begin{tabular}{|c|c|c|c|c|c|}
\hline \multirow[b]{2}{*}{ Organizational Criteria $\left(\mathrm{C}_{\mathrm{j}}\right)$} & \multirow[b]{2}{*}{ Scale } & & \multicolumn{3}{|c|}{ Minimum Maturity Threshold ( $\left.\mathrm{MT}_{\mathrm{ij}}\right)$} \\
\hline & & & RIM 9 & RIM 27 & RIM 17 \\
\hline Product design maturity & {$[1,5]$} & 4.2 & 3 & 1 & 3 \\
\hline Project management maturity & {$[1,5]$} & 3.8 & 3 & 1 & 3 \\
\hline Risk management maturity & {$[1,3]$} & 2.2 & 1 & 2 & 3 \\
\hline Product innovation level & {$[1,3]$} & 2 & 1 & 2 & 3 \\
\hline
\end{tabular}

Table 9 describes the preferences of decision-makers, expressed in terms of minimum thresholds and fuzzy weights (using a linguistic scale) for criteria $\mathrm{C}_{5}$ to $\mathrm{C}_{12}$.

Table 9: Decision-Makers' Preferences on criteria $\mathrm{C}_{5}$ to $\mathrm{C}_{12}$

\begin{tabular}{llll} 
& Scale & Minimum threshold $\left(\mathrm{MT}_{\mathrm{j}}\right)$ & $\begin{array}{c}\text { Fuzzy } \\
\left(\mathrm{FW}_{\mathrm{j}}\right)\end{array}$ \\
\hline Preference Criteria $\left(\mathrm{C}_{\mathrm{j}}\right)$ & $\mathrm{Weight}$ \\
\hline Simplicity of use & {$[1,3]$} & $\mathrm{VH}$ & $\mathrm{A}$ \\
Interaction considerations & {$[1,3]$} & 2 & $\mathrm{VL}$ \\
Completeness & {$[1,3]$} & 1 & $\mathrm{VL}$ \\
Number of characteristics & {$[1,3]$} & 1 & $\mathrm{VL}$ \\
Types of data & {$[1,3]$} & 2 & $\mathrm{H}$ \\
Graphical display & {$[1,3]$} & 2 & $\mathrm{VL}$ \\
Specificity & {$[1,3]$} & 2 & $\mathrm{~A}$
\end{tabular}

Following this, two meetings were conducted to run the selection process using our structured approach. At the first meeting, the group was introduced to the methodology, including basic multi-criteria decision-making theory and basic fuzzy set theory. Then, the process of screening out some methods was explained and conducted. This enabled to understand the reasons why some methods were removed and others not. The second meeting took place a few days after the first one. At the beginning of the second meeting, the participants were given a chance to review and revise their decision parameters. No modification was suggested, but this has to be analyzed with caution, since it depends on the number of alternatives which are screened out (eventually conducting to zero remaining alternatives, which makes these modifications mandatory), and since no important method according to the decision-makers was screened out (eventually leading to the suggestion of relaxing some thresholds in order to include this method in the feasibility space). This point is in our opinion strongly related to the particular case of the organization, and no generalization can be made for the moment.

\section{2. $\quad$ Analysis and managerial insights}

Due to the low maturity level in risk management and due to the innovative level of the product, it was difficult for the company to implement methods with high requirements in these fields. 15 RIM and 7 RAM were screened out at the first step, since the organization was not mature enough to implement them properly (comparison between tables 6 and 8 ).

The second filtering step screened out 11 RIM and 9 RAM, since they did not fit with minimum requirements of decision-makers (comparison between tables 7 and 9). The three criteria with a minimum threshold of 1 were not significant for screening out, but the other criteria were important in this step as they helped to reduce the number of alternatives.

For the final ranking step, only 6 RIM (3, 18, 20, 25, 27 and 29) and 3 RAM (3, 7 and 9) were still candidates. The best solution and the worst feasible solution $\mathrm{PRM}^{\mathrm{max}}$ and $\mathrm{PRM}^{\mathrm{min}}$ were defined (using the minimum thresholds of table 9 for PRM $^{\mathrm{min}}$ ). The positive distance $\mathrm{d}^{\mathrm{max}}$ and negative distance $\mathrm{d}^{\mathrm{min}}$ are calculated using equation 7 and displayed in table 10. 
Table 10: Illustration of the ranking results by calculation of the closeness coefficient on the Tramway example

\begin{tabular}{|c|c|c|c|}
\hline $\mathrm{PRM}_{\mathrm{i}}$ & $\mathrm{d}_{\mathrm{i}}^{\max }$ & $\mathrm{d}_{\mathrm{i}}^{\min }$ & $\mathrm{CC}_{\mathrm{i}}$ \\
\hline $\begin{array}{l}\text { RIM } 3\left(\mathrm{PRM}_{3}\right) \\
\text { Scenario analysis }\end{array}$ & $\mathrm{d}_{3}{ }^{\max }=0.3$ & $\mathrm{~d}_{3}{ }^{\mathrm{min}}=0.09$ & $\mathrm{CC}_{3}=0.61$ \\
\hline $\begin{array}{l}\text { RIM } 18 \\
\text { Fault tree or cause tree }\end{array}$ & $\mathrm{d}_{18}{ }^{\max }=0.35$ & $\mathrm{~d}_{18}{ }^{\mathrm{min}}=0.04$ & $\mathrm{CC}_{18}=0.66$ \\
\hline $\begin{array}{l}\text { RIM } 20 \\
\text { Ishikawa (fishbone diagram) }\end{array}$ & $\mathrm{d}_{20}{ }^{\max }=0.14$ & $\mathrm{~d}_{20}{ }^{\mathrm{min}}=0.25$ & $\mathrm{CC}_{20}=0.45$ \\
\hline $\begin{array}{l}\text { RIM } 25 \\
\text { Expert judgment, Delphi method }\end{array}$ & $\mathrm{d}_{25}{ }^{\max }=0.19$ & $\mathrm{~d}_{25}{ }^{\mathrm{min}}=0.19$ & $\mathrm{CC}_{25}=0.5$ \\
\hline $\begin{array}{l}\text { RIM } 27 \\
\text { Brainstorming }\end{array}$ & $\mathrm{d}_{27}{ }^{\max }=0.14$ & $\mathrm{~d}_{27}{ }^{\mathrm{min}}=0.25$ & $\mathrm{CC}_{27}=0.45$ \\
\hline $\begin{array}{l}\text { RIM } 29 \\
\text { Check-lists }\end{array}$ & $\mathrm{d}_{29}{ }^{\max }=0.09$ & $\mathrm{~d}_{29}{ }^{\mathrm{min}}=0.30$ & $\mathrm{CC}_{29}=0.39$ \\
\hline $\begin{array}{l}\text { RAM } 3\left(\mathrm{PRM}_{35}\right) \\
\text { Fault tree or cause tree }\end{array}$ & $\mathrm{d}_{35}{ }^{\max }=0.04$ & $\mathrm{~d}_{35}{ }^{\mathrm{min}}=0.35$ & $\mathrm{CC}_{35}=0.35$ \\
\hline $\begin{array}{l}\text { RAM } 7\left(\text { PRM }_{39}\right) \\
\text { Bow tie (cause-consequence diagram) }\end{array}$ & $\mathrm{d}_{39}{ }^{\max }=0.08$ & $\mathrm{~d}_{39}{ }^{\mathrm{min}}=0.31$ & $\mathrm{CC}_{39}=0.38$ \\
\hline $\begin{array}{l}\text { RAM 9 }\left(\text { PRM }_{41}\right) \\
\text { Monte-Carlo simulation }\end{array}$ & $\mathrm{d}_{41}{ }^{\max }=0.13$ & $\mathrm{~d}_{41}{ }^{\mathrm{min}}=0.25$ & $\mathrm{CC}_{41}=0.44$ \\
\hline
\end{tabular}

The final combination in this case was a choice between RIM 29, 27 and 20 and between RAM 3 and 7. The remaining RIM candidates were diverse, with creativity-based methods (brainstorming), experience-based methods (check-lists) and expertise-based methods (expert judgment). Some of them like cause tree or Ishikawa are applicable in all situations, with or without experience. The remaining RAM candidates mainly focused on causeeffect modeling and analysis.

In the first place, the decision-makers decided to proceed with an in-depth analysis, so the choice of experience or expertise-based methods was made. However, some space was left for creativity, locally applied to new or innovative parts of the project. Indeed, from oneproject to another, 80-90\% of decisions are recurrent and 10-20\% is new.

Secondly, they decided to focus on cause and effect relationship analysis. This explains why Ishikawa was chosen, even if its closeness coefficient score was not the best. For RAM, the choice was a cause-consequence diagram (also called bow tie or butterfly diagram). The compatibility ratio is good since both methods are based on cause and effect modeling. They also decided to implement brainstorming to local and novel parts of the projects.

In this case, all the potential solutions are easy to understand and to use. So, the organizational cost of implementation does not change the final choice; it is not necessary to make a trade-off.

The growing complexity of projects involves a huge number of cause-effect relationships between parameters, resources and events. These relationships can cause unwanted surprises like chain reactions or loops, which are quite impossible to detect in the current situation. The current PRM method implemented in the organization was a simple list of risks with probability and gravity assessment (combination of RIM 8 and RAM 2). It is mainlybased on independent analysis and treatment of risks. The decision-makers noticed the gap between their preferences, which involve the choice of interactions-based methods, and the current implemented method.

They were confident that the proposed ranking corresponded to organizational needs (for this type of project). In particular, the fact that the current method is eliminated in our approach was initially a surprise, but it was accepted since accompanying explanations were clear. Moreover, even if decision-makers agreed with the methodological recommendation, they predicted a significant effort to change from the current situation to the desired one. This is due to the fact that the maturity of the teams in risk management is very low. Difficulties in understanding the benefit of including cause-effect relationships between risks inside the global process can ensue. 


\section{Conclusions and perspectives}

\subsection{Synthesis of the approach}

This study points out that there are many Project Risk Management methods, which focus mainly on risk identification and risk analysis. Nevertheless, there is a lack of assistance to decision-makers to select the most suitable method for their projects. In this paper, we propose an approach to help choose the right PRM method. The proposal is a nine-step multi-criteria decision-making process. The first three steps consist in modeling the decision problem. The following three steps consist in capturing data about the organization and the decision-makers' preferences. The last three steps screen out methods which are too ambitious compared to the organization's maturity, and then screen out and rank remaining methods according to decision-makers' preferences. Some refinements can be added by considering gap analysis, compatibility between methods and organizational cost. As some judgments are given in linguistic terms, fuzzy numbers are applied in this study to determine the weights.

\subsection{Discussion and perspectives for future research}

There are severalpoints to be raised about the sensitivity and robustness of the final result.

About the completeness of the initial lists. The list of methods is quite representative both of what exists in the literature and what is really applied in companies. The list of criteriadiffers as it is our own creation. But the validity of this list has been tested by studying and analyzing the characteristics of the methods in the literature and by locally validating it by experts of the considered organization. There may be other relevant criteria to take into account when choosing PRM methods, but they have to be appropriate in the context. A complete Delphi study could result in a more generic level of validity, but there is a risk of encountering difficulty in reaching a consensus with many experts who have widely differing levels of expertise regarding the 51 methods and significantly different fields of application. Finally, we think that there is more a need for a combination of existing methods than for new methods.

About the evaluation of the methods.Some preliminary assessments were made, using threshold definitions and qualitative assessments of methods regarding the twelve criteria. The final results are sensitive to these inputs, but the thresholds were assessed by interviews and literature review. Secondly, it is necessary to use qualitative scales as no obvious quantitative parameters exist.

About the decision-makers' preferences and evaluation of the company. The application of the process to a reallife example raises some questions about DM: what is the sensitivity of this model to decision-makers' unreliability? Who should use it and when? Should it be used at corporate level (project office) or by the project manager before starting the project, or by a combination of both levels?

About the decision-making process.We wanted to test the principles of this Multi Criteria Decision Making model. To this end, a simple model was developed in order to apply it to an industrial example without prerequisites. This is a first step towards a more robust model, but at this stage, it has given some promising results. Complementary fieldwork is currently being carried out on the use of outranking methodologies, like Electre Tri for weighting preferences. This will give a more precise evaluation of weights, since criteria will be compared pair wise.

\subsection{Added value of our approach}

Finally, we argue that this decision-making process has an added value for the Project Risk Management process of the company, as well as for the global project management process. Namely, a more suitable PRM method will enable a reduction of the impact of risks and of the probability of these risks occurring. So, both the rate of success and performance level of projects could potentially be improved. One further development could be to use this decision-making process as a functional requirement definition of a good PRM method, and then to develop a specific and more suitable method. This method could be developed by compilation of existing methods or by specific development. Moreover, we think that evaluating existing methods may help identify some conceptual or practical shortcomings of these methods. For instance, we have found very few PRM methods that can properly handle the interaction between risks. Finally, we think that this study will increase managerial awareness of all available PRM methods, and that it will lead them to consider the choice of method as a strategic decision that could have an impact on project success. 


\title{
Appendix A: List of Risk Analysis Methods (RAM)
}

\author{
Table 10 : List of RAM
}

\begin{tabular}{|c|c|c|}
\hline Code & Complete Name & Description \\
\hline RAM1 & $\begin{array}{l}\text { Failure Mode, Effects (and Criticality) } \\
\text { Analysis (FMEA or FMECA) }\end{array}$ & $\begin{array}{l}\text { Consists of assessment of dysfunctions modes, effects and their criticality } \\
\text { (probability and gravity). }\end{array}$ \\
\hline RAM2 & Preliminary Risk Analysis (or Hazard) & $\begin{array}{l}\text { Assesses potential dangerous elements, dangerous situations, hazards and then } \\
\text { dangers (with probability) and their consequences (with gravity). }\end{array}$ \\
\hline RAM3 & $\begin{array}{l}\text { Fault Tree Analysis (Failure tree or } \\
\text { Dysfunction tree) or Cause Tree }\end{array}$ & Evaluates the conditions and their probability which conduct to an event. \\
\hline RAM4 & $\begin{array}{l}\text { Information System Risk Analysis and } \\
\text { Management Methodology (ISRAMM) }\end{array}$ & Focused on risks linked with information and information systems in the project. \\
\hline RAM5 & Event tree & Evaluates the consequences of an event. \\
\hline RAM6 & Hazard Operability (HAZOP) & $\begin{array}{l}\text { Identifies the consequences of variance in components parameters. Variances are } \\
\text { expressed by No, More, Less, Before, After. }\end{array}$ \\
\hline RAM7 & $\begin{array}{l}\text { Bow tie or Cause-Consequence } \\
\text { Diagram }\end{array}$ & $\begin{array}{l}\text { Consists of focusing on a single risk and analyzing its causes (event tree) and } \\
\text { consequences (dysfunction tree). }\end{array}$ \\
\hline RAM8 & Markov chain state graph & $\begin{array}{l}\text { Identification of the whole possible states of the project system, including normal } \\
\text { and altered states. Focused on transitions from a state to another, and } \\
\text { consequences for the rest of the project. }\end{array}$ \\
\hline RAM9 & Monte-Carlo simulation & $\begin{array}{l}\text { Includes different durations (or costs) for each task and simulates the possible } \\
\text { scenarii. Delivers a probability distribution (cumulative or not) for project global } \\
\text { duration (or cost). }\end{array}$ \\
\hline RAM10 & $\begin{array}{l}\text { Analysis of Dysfunctions } \\
\text { Information in a Project (ADIP) }\end{array}$ & $\begin{array}{l}\text { Method focused on information aspect of project. Based on a PRA followed by a } \\
\text { Project FMECA limited to information risks. }\end{array}$ \\
\hline RAM11 & Contingency Assessment & $\begin{array}{l}\text { Method based on return of experience which consists of using previous project } \\
\text { data in order to assess current project risks. Consequence is assessment of } \\
\text { mandatory contingency reserves. }\end{array}$ \\
\hline RAM12 & Bayesian Network & $\begin{array}{l}\mathrm{BN} \text { or } \mathrm{BBN} \text { (Bayesian belief network) is a probabilistic model that represents a } \\
\text { set of random variables and their conditional dependences via a directed acyclic } \\
\text { graph. }\end{array}$ \\
\hline RAM13 & Scoring Methodology & $\begin{array}{l}\text { Developed in pharmaceutical industry in order to evaluate risk exposure of } \\
\text { product development projects. It assesses market attractiveness, product } \\
\text { competitiveness, and technological feasibility and development costs. These } \\
\text { criteria are used to evaluate graphically global project risk by analysis of the plots } \\
\text { positions, surface and angles. }\end{array}$ \\
\hline RAM14 & $\begin{array}{l}\text { Hazard analysis Critical Control Points } \\
\text { (HACCP) }\end{array}$ & $\begin{array}{l}\text { Identifies Critical Control Points in the production phase. Hazards are identified } \\
\text { and assessed at each phase of the process. }\end{array}$ \\
\hline RAM15 & $\begin{array}{l}\text { System Dysfunctions Analysis } \\
\text { Methodology (SDAM) }\end{array}$ & $\begin{array}{l}\text { Analyses dangers and chain relations between these dangers. Consists of a } \\
\text { probabilistic approach which enables to identify a danger's occurrence } \\
\text { probability, and of a deterministic approach which enables to assess the } \\
\text { effectiveness of the barriers if danger occurs. }\end{array}$ \\
\hline RAM16 & Analysis of Program Risk (APR) & $\begin{array}{l}\text { Identifies and analyses cause-consequence couples, where causes are project } \\
\text { activities which may cause risks (technical tasks, planning, team management, } \\
\text { supply, marketing, ...) and consequences are categorized (delay, cost, technical, } \\
\text { juridical, ...) }\end{array}$ \\
\hline RAM17 & $\begin{array}{l}\text { Analysis of Dysfunctions and Risks in } \\
\text { Operations (ADR) }\end{array}$ & Risk categorization method among two aspects: effect gravity and residual effect \\
\hline RAM18 & Estimation Risk Analysis (ERA) & $\begin{array}{l}\text { Cost probability distribution calculation. Based on Monte-Carlo analysis. Takes } \\
\text { into account uncertainty in cost variance and dependence between costs. Uses } \\
\text { triangle distribution. }\end{array}$ \\
\hline RAM19 & Design Risk Analysis (DRA) & $\begin{array}{l}\text { User vulnerability integration. Analysis of product normal use and altered use for } \\
\text { risk identification. Focused on product risks, but allows to generate associated } \\
\text { project risks (delays, cost overruns, technical non-acceptance) }\end{array}$ \\
\hline
\end{tabular}




\section{Appendix B: Fuzzy set theory}

Most of the preferences of the decision-makers are expressed by using linguistic expression, such as "very likely ", "highly preferable", "do not like". They involve the use of fuzzy set theory, introduced by (Zadeh 1965; Zadeh 1975), and first applied to decision-making by (Bellman and Zadeh 1970). Some definitions are given for usage in this paper, extracted from several references, like (Kaufmann and Gupta 1991; Zimmermann 1991; Klir and Yuan 1995).

Definition 1 : a fuzzy set $\tilde{\mathrm{n}}$ in a universe of discourse $\mathrm{X}$ is characterized by a membership function $\mu_{\tilde{\mathrm{n}}}(\mathrm{x})$, which associates with each element $\mathrm{x}$ in $\mathrm{X}$ a real number in the interval $[0,1]$. The function value $\mu_{\tilde{n}}(\mathrm{x})$ is termed the grade of membership of $\mathrm{x}$ in $\tilde{\mathrm{n}}$ (Kaufmann and Gupta 1991).

Definition 2 : a fuzzy set $\tilde{n}$ is convex if and only if (Klir and Yuan 1995):

$\mu_{\tilde{\mathrm{n}}}\left(\lambda * x_{1}+(1-\lambda) * x_{2}\right) \geq \min \left(\mu_{\tilde{\mathrm{n}}}\left(x_{1}\right), \mu_{\tilde{\mathrm{n}}}\left(x_{2}\right)\right.$

for all $\left(\mathrm{x}_{1}, \mathrm{x}_{2}\right)$ in $\mathrm{X}$ and $\lambda$ in $[0,1]$

Definition 3: a fuzzy set $\tilde{n}$ is normalized if its height is equal to 1 (Klir and Yuan 1995). The height is the largest membership grade attained for any $\mathrm{x}$ in $\mathrm{X}$.

Definition 4 : a fuzzy number is a fuzzy set that is both convex and normal (Kaufmann and Gupta 1991).

Definition $5:$ a positive triangular fuzzy number $\tilde{n}$ can be defined as $\left(\mathrm{n}_{1}, \mathrm{n}_{2}, \mathrm{n}_{3}\right)$, with the following membership function $\mu_{\tilde{\mathrm{n}}}(\mathrm{x})$ :

$\mu_{\tilde{\mathrm{n}}}(x)=\left|\begin{array}{c}0 \text { if } x<n_{1} \\ \frac{x-n_{1}}{n_{2}-n_{1}} \text { for } x \in\left[n_{1}, n_{2}\right] \\ \frac{n_{3}-x}{n_{3}-n_{2}} \text { for } x \in\left[n_{2}, n_{3}\right] \\ 0 \text { if } x>n_{3}\end{array}\right|$

The fuzzy number is symmetrical iff $\mathrm{n}_{2}=\left(\mathrm{n}_{1}+\mathrm{n}_{3}\right) / 2$.

Definition 6: a linguistic variable is a variable whose values are linguistic terms, like very low, low, medium, high and very high. Fuzzy numbers can represent these linguistic values in situations where quantitative expressions or reliable qualitative expressions are not possible. In this paper, positive triangular fuzzy numbers are used to express linguistic variables.

Definition $7:$ in the case where several fuzzy numbers $\tilde{\mathrm{n}}^{\mathrm{k}}$ are defined, the addition is a fuzzy number $\tilde{\mathrm{n}}$ defined as follows . For each $\lambda$ between 0 and 1 , the $\lambda$-cut of the sum of the numbers is the sum of the $\lambda$-cut of each number.

$\bigoplus \tilde{n}^{k}=\left[n_{1}, n_{2}, n_{3}\right]$ with $n_{i}=\sum_{k} n_{i}^{k}$ for $i=1$ to 3 .

The average opinion of several decision-makers is then obtained by dividing this fuzzy number by the number of decision-makers $\mathrm{Nd}$, which is expressed in equation (5).

Another formulation was introduced by (Amiri et al. 2009):

$n_{1}=\min _{k} n_{1}^{k}, n_{2}=\frac{\sum_{k} n_{2}^{k}}{N d}, n_{3}=\max _{k} n_{3}^{k}$

However, we decided to use the first formulation since it averages out the opinions of decision-makers, instead of keeping the extreme values.Some methodologies have been developed thanks to the use of fuzzy set theory, like fuzzy Standard Additive Weighting model, fuzzy weighted product model, fuzzy AHP, revised fuzzy AHP and fuzzy TOPSIS, studied and compared in (Triantaphyllou and Lin 1996). In our case, we intend to use fuzzy weights, for expression of preferences of the decision-maker on the relativeimportance of criteria. 


\section{References}

AFNOR (1999). RG AERO 000 40, dans NF X50 410. Recommandation générale pour la spécification du management de programme, Editions AFNOR.

AFNOR (2003). FD X 50-117: Management de projet, Gestion du risque, Management des risques d'un projet, AFNOR.

Ahn,B. and K.Park (2008). Comparingmethodsformulti-attributedecision-makingwith ordinalweights,Computers\&OperationsResearch35(2008)1660- 1670.

Amiri, M., M. Zandieh, Soltani, R. and B. Vahdani (2009). "A hybrid multi-criteria decision-making model for firms competence evaluation." Expert Systems with Applications: doi:10.1016/j.eswa.2009.04.045.

APM (1996). Project Risk Analysis \& Management (PRAM) Guide. High Wycombe, ASSOCIATION FOR PROJECT MANAGEMENT.

Athanassopoulos, A. and V. Podinovski (1997), Dominance and potential optimality in multiple criteria decision analysis with imprecise information. Journal of the Operational Research Society, 1997. 48: p. 142-150.

Ayag, Z. and R. G. Ozdemir (2009). "A hybrid approach to concept selection through fuzzy analytic network process." Computers \& Industrial Engineering 56(1): 368-379.

Bass, S. and H. Kwakernaak (1977). "Rating and ranking of multiple-aspect alternatives using fuzzy sets." Automatica 1(1): 4758.

Bellman, R. and L. Zadeh (1970). "Decision-making in a fuzzy environment." Management Science 17: 141-164.

Belton, V. and T. Stewart (2002), Multiple Criteria Decision Analysis: an integrated approach. 2002, Dordrecht: Kluwer.

Bowles, J. (1998). The New SAE FMECA Standard. PROCEEDINGS Annual RELIABILITY and MAINTAINABILITY Symposium

Bryant, D. L. and M. D. Abkowitz (2007). "Estimation of terrestrial chemical spill risks factors using a modified Delphi approach." Journal of Environmental Management 85: 112-120.

BSI (2002). ISO/IEC Guide 73:2002. Risk Management - Vocabulary - Guidelines for use in standards. London, BRITISH STANDARD INSTITUTE.

Carlsson, C. and R. Fuller (2002). "A position paper on the agenda for soft decision analysis." Fuzzy Sets and Systems 131(1): 311.

Chapman, C. and S. Ward (2003). Project risk management - Processes, techniques and insights. . Chichester, UK, John Wiley \& Sons.

Chapman, R. (2001). "The Controlling Influences on Effective Risk Identification and Assessment for Construction Design Management." International Journal of Project Management 19: 147-160.

Chen, S. and C. Hwang (1992). Fuzzy multiple attribute decision-making: methods and applications. Berlin Springer.

Coppendale, J. (1995). "Manage risk in product and process development and avoid unpleasant surprises." Engineering Management Journal.

Dias, L. and J. Clímaco (2000). Additive aggregation with variable interdependent parameters: the VIP analysis software, Journal of the Operational Re- search Society 51 (9) (2000) 1070-1082.

Gautier, R., P. Truchot and T. Gidel (1997). Method of reliability analysis in the project information management process. Managing risks in projects. London, A\&FN SPON: pp.195-203.

Giannopoulos, D. and M. Founti (2010). "A fuzzy approach to incorporate uncertainty in the

PROMETHEE multicriteria method." Int. J. Multicriteria Decision Making 1(1): 80-102.

Hazen, G. (1986), Partial information, dominance and potential optimality in multi-attribute utility theory. Operations Research, 1986. 34: p. 296-310.

Heal, G. and H. Kunreuther (2007). "Modeling interdependent risks." Risk Analysis 27(3): 621-634.

Herrera, F. and E. Herrera-Viedma (2000), Choice functions and mechanisms for linguistic preference relations, European Journal of Operational Research 120 (2000) 144-161.

Henley, E. and H. Kumamoto (1992). Probabilistic risk assessment. New York, IEEE Press.

Hobbs, B. and P. Meier (2000), Energy Decisions and the Environment: a guide to the use of multicriteria methods. 2000, Massachusetts: KLUWER.

IEC (1995). CEI/IEC 300-3-9:1995 Risk Management: part 3 - guide to risk analysis of technological systems. Geneva, INTERNATIONAL ELECTROTECHNICAL COMMISSION.

IEEE (2001). IEEE Standard 1540-2001: standard for software life cycle processes - risk management. New York, INSTITUTE OF ELECTRICAL AND ELECTRONIC ENGINEERS.

IPMA (2006). IPMA Competence Baseline (ICB), Version 3.0, March 2006 International Project Management Association.

ISO (2003). ISO 10006 - Quality Management Systems - Guidelines for quality management in projects. Switzerland, International Organization for Standardization.

Kahraman, C., T. Ertay and G.Buyukozkan (2006). "A fuzzy optimization model for QFD planning process using analytic network approach." European Journal of Operational Research 171: 390-411.

Kangari, R. and S. Leland (1992). "Construction risk assessment by linguistics." IEEE Transactions on Engineering Management: 126-131.

Kaplan, S., S. Vishnepolschi, Zlotin, B. and A. Zusman (1999). New Tools for failure and risk analysis, anticipatory failure détermination (AFD) and the theory of scenario structuring. South-field, Michigan, Monograph published by Ideation International Inc. 
Karacapilidis, N. and C. Pappis (2000), Computer-supported collaborative argumentation and fuzzy similarity measures in multiple criteria decision-making, Computers and Operations Research 27 (2000) 653-671.

Kaufmann, A. and M. Gupta (1991). Introduction to fuzzy arithmetic: theory and application. New York, Van Nostrand Reinhold.

Kawakita, J. (1991). The original KJ method Tokyo, Kawakita Research Intitute.

Keefer, D. (2004). "The underlying event model for approximating probabilistic dependence among binary events." IEEE Transactions on Engineering Management 51(2): 173-182.

Keeney, R. L. and H. Raiffa (1976). Decisions with multiple Objectives. New York, Wiley.

Keizer, J., J. Halman and G. Song (2002). "From experience: applying the risk diagnosing methodology." The journal of product innovation management 19(3): 213-232.

Kerzner, H. (1998). Project management: A Systems Approach to Planning, Scheduling and Controlling New York: John Wiley \& Sons.

Klein, J. and R. Cork (1998). "An approach to technical risk assessment." International Journal of Project Management 16: 345351.

Klir, G. and B. Yuan (1995). Fuzzy sets and fuzzy logic: theory and applications. USA, Prentice Hall Inc.

Kurtoglu, T. and I. Tumer (2007). A graph based framework for early assessment of functional failures in complex systems. DETC 2007., Las Vegas, .

Larichev, O., Olson, D., Moshkovich, H. and A. Mechitov (1995). Numeric vs. cardinal measurements in multi-attribute decision making: How exact is enough? Organizational Behavior and Human Decision Processes 64 (1995) 9-21.

Linstone, H., M. Turoff, et al. (2002). The Delphi method: techniques and applications, Edited by Harold A. Linstone and Murray Turoff.

Lu, L., Zhang, G., Ruan, D. and F. Wu (2007). Multi-objective Group Decision Making: Methods, Software and Applications with Fuzzy Set Technology, Imperial College Press., London, 2007

Lyons, T. and M. Skitmore (2004). "Project risk management in the Queensland engineering construction industry: a survey." International Journal of Project Management 22(1): 51- 61.

Ma, J., Ruan, D., Xu, Y. and G. Zhang (2007). A fuzzy-set approach to treat determinacy and consistency of linguistic terms in multi-criteria decision making, International Journal of Approximate Reasoning 44 (2007) 165-181

Marimin, M., Hatono, I. and H. Tamura (1998). Linguistic labels for expressing fuzzy preference relations in fuzzy group decision making, IEEE Transactions onSystems, Man, and Cybernetics 28 (1998) 205-217

Maytorena, E., G. Winch, Freeman, J. and T. Kiely (2007). "The influence of experience and information search styles on project risk identification performance." IEEE Transactions on Engineering Management 54(2): 315-326.

MIL-STD-1629 (1998). Procedures for performing FMECA (Revision A [1998]).

Miller, G. (1956). "The magical number seven plus or minus two: some limitations on our capacity for processing information." Psychological Review 1956(63): 81-97.

Mohanty, R. P., R. Agarwal, Choudhury, A. K. and M. K. Tiwari (2005). "A fuzzy ANP-based approach to R\&D project selection: a case study." International Journal of Production Research 43: 5199-5216.

Niwa, K. and M. Okuma (1982). "Know-How transfer method and its application to risk management for large construction projects." IEEE Transactions on Engineering Management 29(4): 146-153.

Okoli, C. and S. D. Pawloswki (2004). "The Delphi method as a research tool: an example, design considerations and application." Information \& Management 42: 15-29.

Pareto, V. (1971), Manual of Political Economy (English translation). 1971, New York: AM Kelley Publishers.

PMI, S. C. (2008). A guide to the project management body of knowledge (PMBOK) (2008 ed.). Newton Square, PA, USA. , Project Management Institute.

PRINCE (1999). Managing Successful Projects with PRINCE 2, UK: Computers and Telecommunications Agency (CCTA).

Riek, R. (2001). "From experience: Capturing hard-won NPD lessons in checklists. ." The Journal of Product Innovation Management 18: 301-313.

Rios Insua, D. (1990), Sensitivity Analysis in Multiple Objective Decision Making. 1990, Berlin: Springer-Verlag.

Roy, B. (1996), Multicriteria methodology for decision aiding. 1996, Dordrecht: Kluwer

Roy, B. (2010). "Two conceptions of decision aiding." Int. J. Multicriteria Decision Making 1(1): 74-79.

Salo, A. and R. Hämäläinen (2001). Preference ratio in multi-attribute evaluation (PRIME) - elicitation and decision procedures under incomplete information, IEEE Transactions on Systems, Man and Cybernetics: Part A 31 (6) (2001) 533-545.

Schmucker, K. (1984). Fuzzy Sets, Natural language computations and Risk Analysis. Rockville, MD, Computer Science Press.

Scott, M. (2007). "Quantifying uncertainty in multicriteria concept selection methods." Research in Engineering Design 17: 175187.

Shamsuzzaman, M., A. Sharif Ullah and E. Bohez (2003). "Applying linguistic criteria in FMS selection: Fuzzy-set AHP approach." Integrated Manufacturing Systems 14(3): 247-254.

Shimizu, H. and H. Noguchi (2005). "Reliability Problem Prevention Method for Automotive Components-Development of GD'3' Activity and DRBFM method for Stimulating Creativity and Visualizing Problems, ." Transaction of Society of Automotive Engineers of Japan, 36(4): 163-168.

Skulmoski, G. J., F. T. Hartman and J. Krahn (2007). "The Delphi Method for Graduate Research." The Journal of Information Technology Education 6.

Smith, P. and G. Merritt (2002). Proactive Risk Management. Controlling Uncertainty in Product Development. New York:, Productivity Press. 
Stamatelatos, M. (2004). A Vision for System Safety Enhancement at NASA, . Safety Directors’ Meeting, Cocoa Beach, Florida,.

Steuer, R., Gardiner L. and J. Gray (1996). A bibliographic survey of the activities and international nature of multiple criteria decision-making, Journal of Multi-criteria Decision Analysis 5 (1996) 195-217.

Stone, R., I. Tumer and M. Van Wie (2004). "The function-failure design method." Journal of Mechanical Design 127(3): 397407.

Tah, J. and V. Carr (2000). "A proposal for construction project risk assessment using fuzzy logic." Construction Management and Economics 18: 491-500.

Triantaphyllou, E. and C. Lin (1996). "Development and evaluation of five fuzzy multi-attribute decision-making methods." International Journal of Approximate Reasoning 14: 281-310.

Tumer, I. and R. Stone (2001). "Mapping function to failure mode during component development." Research in Engineering Design 14(1): 25-33.

Vincke, P. (1992), Multi-criteria decision-aid. 1992, New York: Wiley.

Weber, M. (1987). Decision making with incomplete information, European Jour-nal of Operational Research 28 (1987) $44-57$.

Wirba, E., J. Tah and R. Howes (1996). "Risk interdependencies and natural language computations." Engineering construction and architectural management 3(4): 251-269.

$\mathrm{Xu}, \mathrm{X}$. (2004). Uncertain linguistic aggregation operators based approach to multiple attribute group decision making under uncertain linguistic environment, Information Sciences 168 (2004) 171-184.

Zadeh, L. (1965). "Fuzzy sets." Information and Control 8: 338-353.

Zadeh, L. (1975). "The concept of a linguistic variable and its application to approximate reasoning." Information Sciences 8(1): 199-249.

Zhang, G. and J. Lu (2003), An integrated group decision making method with fuzzy preference for alternatives and individual judgments for selection criteria, Group Decision and Negotiation 12 (2003) 501-515.

Zhang, G. and J. Lu (2009). "A linguistic intelligent user guide for method selection in multi-objective decision support systems." Information Sciences 179: 2299-2308.

Zimmermann, H. (1991). Fuzzy set theory - And its applications Springer. 